\title{
An in vitro method for assessment of amino acid bidirectional transport and intracellular metabolic fluxes in mammary epithelial cells
}

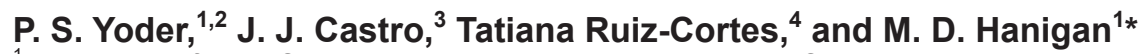 \\ ${ }^{1}$ Department of Dairy Science, Virginia Polytechnic Institute and State University, Blacksburg 24061 \\ ${ }^{2}$ Perdue AgriBusiness LLC, Salisbury, MD 21804 \\ ${ }^{3}$ Dairy Visions LLC, Chandler, AZ 85249 \\ ${ }^{4}$ Faculty of Agricultural Sciences, Universidad de Antioquia, Medellin, Colombia, 050010
}

\begin{abstract}
Understanding uptake of AA by mammary tissue as supply varies is critical for predicting milk component production. Our objective was to develop an in vitro method to quantify cellular uptake, efflux, and intracellular metabolism of individual AA that could be implemented for evaluating these factors when AA supply and profile are varied. Bovine primary mammary epithelial cells were grown to confluency and exposed to medium with an AA profile and concentration similar to lactating dairy cow plasma for $24 \mathrm{~h}$. Cells were then preloaded in medium enriched with ${ }^{15} \mathrm{~N}$-labeled AA for $24 \mathrm{~h}$ followed by removal of the ${ }^{15} \mathrm{~N}$-labeled medium and incubation with medium enriched with ${ }^{13} \mathrm{C}$-labeled AA for $0,15,60,300,900,1,800$, and 3,600 s. Extracellular free AA and intracellular free and protein-bound AA were analyzed for concentrations and isotopic enrichment by gas chromatography-mass spectrometry. A dynamic, 12-pool model was constructed representing extracellular and intracellular free and protein-bound pools of an $\mathrm{AA}$, and their respective ${ }^{15} \mathrm{~N}$ and ${ }^{13} \mathrm{C}$ isotopes. Markov chain Monte Carlo simulation ( $\mathrm{n}=$ 5,000 ) was conducted to evaluate prediction errors by deriving standard errors and posterior distributions for rate constants, fluxes, and pools. Cellular Ala influx and efflux were higher than Leu, reflecting Ala role in driving system L transport and the high capacity of sodium-dependent transport. The Ala and Leu turnover rates were 181 and 95, 580 and 857, and 74 and $157 \%$ per hour for extracellular, intracellular, and fast protein-bound pools, respectively. The intracellular and extracellular Ala to Leu ratios were quite different, meaning the blood AA profile is not the AA profile provided for protein translation. The high level of exchange
\end{abstract}

Received January 4, 2020.

Accepted April 18, 2020.

*Corresponding author: mhanigan@vt.edu and rapid turnover of pools provide a mechanism for matching the AA supplies to the precision necessary for translation. This also understates the importance of using experimental medium similar to what is observed in vivo given that some $\mathrm{AA}$ depend on other $\mathrm{AA}$ for influx (exchange driven). The average root mean squared prediction error across the isotope enrichments, pools, and concentrations was 9.7 and $14.1 \%$ for Ala and Leu, respectively, and collinearity among parameters was low, indicating adequate fit and identifiability. The described model provides insight on individual AA transport kinetics and a method for future evaluation of AA transport and intracellular metabolism when subjected to varying AA supplies.

Key words: amino acids, transport, isotope, Ala, Leu

\section{INTRODUCTION}

Udder AA uptake from arterial supplies and synthesis into milk proteins is relatively low. Only $22 \%$ of arterial AA daily influx is transformed into milk protein, although it varies considerably across AA (Arriola Apelo et al., 2014). If more AA could be taken up by the udder cells, then exiting venous blood would have lower AA concentrations. Lower AA venous concentrations will reduce splanchnic catabolism because these tissuebeds extract AA by mass action (Hanigan et al., 2004). The splanchnic catabolism of AA is the primary culprit of the low $\mathrm{N}$ efficiency with milk production from dairy cows (Hristov et al., 2004; Arriola Apelo et al., 2014).

Intracellular AA concentrations partially regulate milk protein synthesis rate (Cant et al., 2018). If linear (mass action) net AA uptake is assumed by the udder, decreasing or increasing dietary MP supplies would change intracellular AA concentrations and thus milk protein synthesis rate. To make a sizable increase in $\mathrm{N}$ efficiency (30\% gross efficiency), maintaining or increasing udder cell AA concentrations would be required when MP supplies are reduced. This could be achieved by increased cellular AA transport efficiency. 
Amino acids can enter mammary epithelial cells via 3 mechanisms: passive diffusion, sodium-driven gradient, or AA exchange (Taylor, 2014). Active transporters lack high specificity. Some transporters work with up to a dozen AA and AA can use multiple transporter systems (Christensen, 1990). The active transporters can build up steep intracellular concentration gradients relative to extracellular concentrations ("loaders"), whereas others act as exchangers ("harmonizer") to catalyze transport of other AA (Bröer and Bröer, 2017). In the mammary glands of cows, these "loader" transporters consist of system A, system Gly, system $\mathrm{N}$, system $\mathrm{X}_{-\mathrm{ag}}$, and system $\mathrm{y}+$ (Shennan and Boyd, 2014). The "harmonizer" transporters consist of system ASC, system L, and system y+L. Another class of transporters reacts to short-term AA deprivation by increasing expression and activity. These are referred to as "rescue" transporters [i.e., SNAT2 within system A and CAT-1 within system y+ (Bröer and Bröer, 2017)]. Amino acid transporters likely have evolved to manage the variation in daily influx of AA so that intracellular concentrations are better matched to protein synthesis needs (Christensen, 1990). Net flux of an AA often can be quite different than influx and efflux, and the bidirectional flows confer more flexibility than that which could be achieved with a single, unidirectional flux.

Previously, net AA fluxes were observed to exhibit mass action responses to arterial AA supplies in lactating dairy cows and pig mammary tissue explants (Hanigan et al., 1992; Hurley et al., 2000; Jackson et al., 2000). Many experimental protocols have evaluated a single AA with various competitor AA or inhibiting molecules on kinetics and transporter activity (Tovar et al., 2000). However, the AA concentrations evaluated are usually quite different from in vivo, and the interaction with the transport of all the other 19 AA has not been assessed. Studies of AA transport should consider that individual AA uptake is not univariate, but likely a 20 dimension problem (Christensen, 1990). Additionally, measuring the enrichment of an isotope intracellularly will provide some information on net uptake, but it does not allow derivation of unidirectional uptake or intracellular metabolism. Knowledge of the AA unidirectional uptake kinetics are necessary for better predicting how intracellular AA concentrations change when MP supplies are varied.

The objectives of this study were to develop an in vitro method for simultaneous measurements of bidirectional transport and intracellular metabolism of multiple AA. We hypothesized that use of 3 unique isotopic labels per AA and the construction and fitting of a dynamic 12-pool model to the data will address our objectives.

\section{MATERIALS AND METHODS}

\section{Experimental Design, Materials, and Protocol}

Bovine primary mammary epithelial cells were obtained from the State Key Laboratory of Animal Nutrition, Institute of Animal Science, Chinese Academy of Agricultural Sciences, Beijing, China, and evaluated for being bovine and epithelial in origin (Yoder et al., 2019). Cells were seeded on two 89.4-mm $\times 19.2-\mathrm{mm}$ tissue culture-treated polystyrene cell culture dishes (\#353003, Corning Inc., Corning, NY) at a density of $1.9 \times 10^{6}$ cells per dish and incubated at $37^{\circ} \mathrm{C}$ under $5 \% \mathrm{CO}_{2}$ (HERAcell 150i, Thermo Fisher Scientific, Waltham, MA). The culture growth medium was DMEM/F-12 (\#D8900, Sigma-Aldrich, St. Louis, MO) with the following additions: $10 \%$ fetal bovine serum, $5 \mathrm{mg} / \mathrm{L}$ bovine insulin (\#700-112P, Gemini Bio-Products, Sacramento, CA), $5 \mathrm{mg} / \mathrm{L}$ prolactin (\#L6520, Sigma-Aldrich), $5 \mathrm{mg} / \mathrm{L}$ progesterone (\#P7556, Sigma-Aldrich), $5 \mathrm{mg} / \mathrm{L}$ transferrin (\#T8158, SigmaAldrich), $0.01 \mathrm{mg} / \mathrm{L}$ epidermal growth factor (\#E4127, Sigma-Aldrich), $1 \%$ of a $100 \times$ antibiotic-antimitotic mix (\#15240062, Gibco, Waltham, MA), and $1 \mathrm{mg} / \mathrm{L}$ hydrocortisone (\#H0888, Sigma-Aldrich). All media were adjusted to a pH of 7.3 and sterile filtered through a $0.20-\mu \mathrm{m}$ filter (Nalgene Rapid-Flow, \#595-4520, Thermo Fisher Scientific). Cells were cultured for $5 \mathrm{~d}$ and then subsequently transferred to 27 culture dishes $(89.4 \mathrm{~mm} \times 19.2 \mathrm{~mm}$, \#353003, Corning Inc.) and incubated in growth medium. Culture dishes were weighed before addition of cells and medium. Cells were cultured to $90 \%$ confluency and then the growth medium was replaced with a steady-state medium. The steady-state medium consisted of 10\% Earle's balanced salts solution (\#E7510, Sigma-Aldrich), sodium bicarbonate $(2.2 \mathrm{~g} / \mathrm{L})$, D-glucose $(2.151 \mathrm{~g} / \mathrm{L}), 1 \%$ of a $100 \times$ minimal essential medium vitamin solution (\#M6895, Sigma-Aldrich), and the previously described hormones and antibiotics contained in the growth medium. Individual AA were added to the steady-state medium at the average plasma concentration of lactating dairy cows $(\mathrm{DIM}=75 \mathrm{~d}$, milk yield $=45.1 \mathrm{~kg} / \mathrm{d}$; Swanepoel et al., 2016; Supplemental Table S1, https://doi.org/10 $.3168 /$ jds.2020-18155). Cells remained in this steadystate medium for $24 \mathrm{~h}$ before the experiment (medium changed every $12 \mathrm{~h}$ ). A graphical outline of the experiment is provided in Figure 1.

Universally ${ }^{13} \mathrm{C}$-labeled AA derived from algae (U$\left[{ }^{13} \mathrm{C}\right]$, 97-99\% enriched, lot \#30287, product \#CLM1548), universally ${ }^{15} \mathrm{~N}$-labeled AA derived from algae (U- $\left[{ }^{15} \mathrm{~N}\right], 98 \%$ enriched, lot \#24163, product \#NLM2161), and ${ }^{13} \mathrm{C}^{15} \mathrm{~N}$ universally labeled AA derived from 


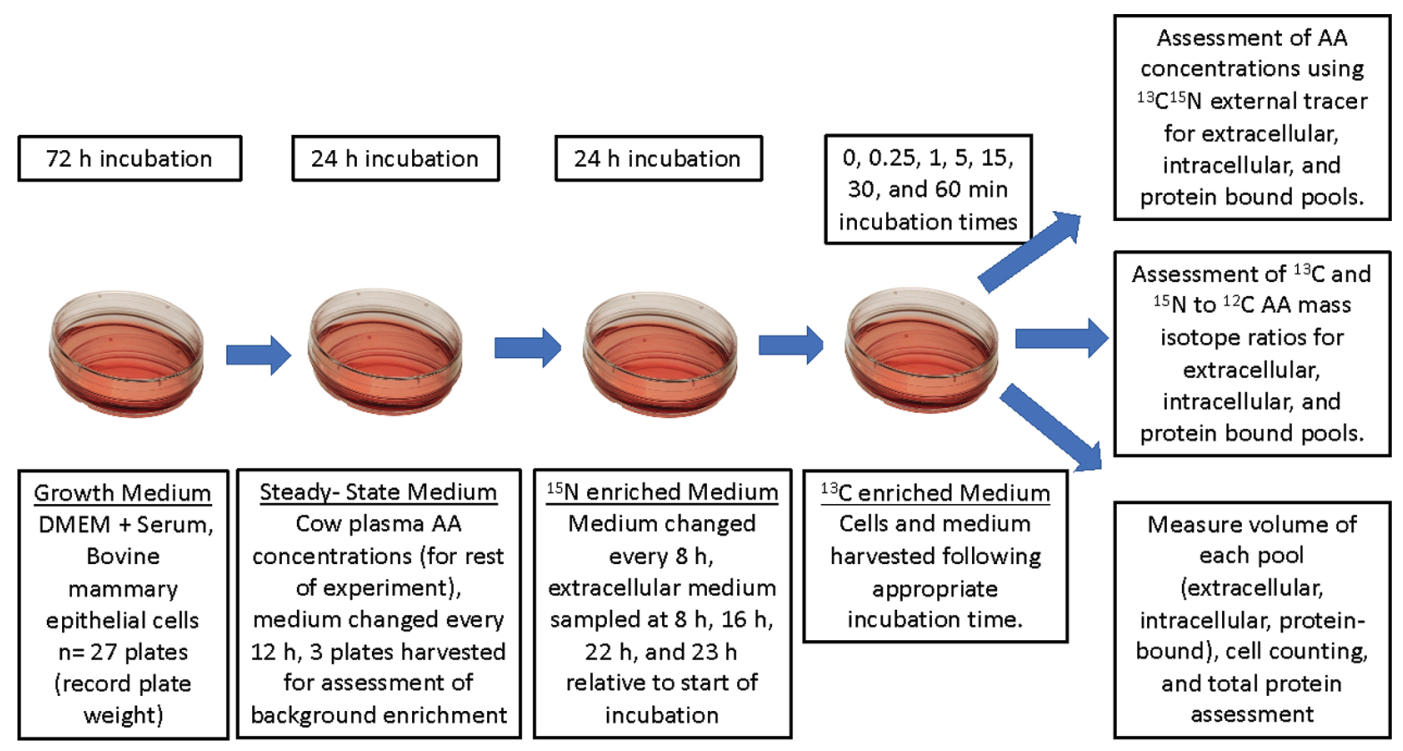

Figure 1. Experimental outline, timeline, media treatments, and measurements of the cell culture experiment for assessment of AA transport. DMEM = Dulbecco's modified Eagle medium.

algae $\left(\mathrm{U}-\left[{ }^{13} \mathrm{C}^{15} \mathrm{~N}\right], 98 \%\right.$ enriched, lot \#16824, product \#CNLM-452) were purchased from Cambridge Isotope Laboratories Inc. (Tewksbury, MA). Amino acid concentrations and profiles of the 3 labeled algae were determined (Supplemental Table S2; https://doi.org/ $10.3168 /$ jds.2020-18155) by measurement of the isotope dilution associated with the addition of a known amount of 18 unlabeled AA (\#AAS18, Sigma-Aldrich) using GC-MS. The enriched algae previously underwent acid hydrolysis; hence, Gln, Asn, Cys, and Trp were not present in the algae. The ${ }^{13} \mathrm{C}^{15} \mathrm{~N}$-enriched algae was also analyzed by HPLC at the University of Missouri for comparison purposes (Supplemental Table S2; https:// doi.org/10.3168/jds.2020-18155). Media mimicking the steady-state medium components and concentrations, except that the AA were enriched with ${ }^{13} \mathrm{C}$-labeled AA or ${ }^{15} \mathrm{~N}$-labeled AA, were formulated. These media will be referred to as ${ }^{13} \mathrm{C}$-enriched medium or ${ }^{15} \mathrm{~N}$-enriched medium (Table 1).

Upon removal of the steady-state medium, cells were washed once with warm PBS $\left(37^{\circ} \mathrm{C}\right)$ and $10 \mathrm{~mL}$ of the ${ }^{15} \mathrm{~N}$-enriched medium was added per plate. Cells were incubated $24 \mathrm{~h}$ in ${ }^{15} \mathrm{~N}$-enriched medium that was changed every $8 \mathrm{~h}$ to minimize the effects of AA depletion. During the ${ }^{15} \mathrm{~N}$ incubation, $0.4 \mathrm{~mL}$ of medium was sampled at $8,16,22$, and $23 \mathrm{~h}$ from 3 plates and stored at $-20^{\circ} \mathrm{C}$ to assess extracellular AA concentrations and enrichment. Following $24 \mathrm{~h}$ of ${ }^{15} \mathrm{~N}$ incubation, cells were washed twice with warm $\mathrm{PBS}\left(37^{\circ} \mathrm{C}\right)$, and 6 $\mathrm{mL}$ of warm ${ }^{13} \mathrm{C}$-enriched medium $\left(37^{\circ} \mathrm{C}\right)$ was added to the cells. Cells were incubated with the ${ }^{13} \mathrm{C}$-enriched medium for $0 \mathrm{~s}, 15 \mathrm{~s}, 1 \mathrm{~min}, 5 \mathrm{~min}, 15 \mathrm{~min}, 30 \mathrm{~min}$, and $60 \mathrm{~min}$. The zero time point was utilized to correct for extracellular medium contamination of intracellular AA during cell lysis (Darmaun et al., 1988). Other selected time points were based on preliminary experiments (data not shown). At each of the time points, 1 $\mathrm{mL}$ of medium was removed from the plate, placed into ice-cold $1.5-\mathrm{mL}$ tubes, and stored at $-20^{\circ} \mathrm{C}$. Following medium removal, cells were rinsed 3 times with ice-cold PBS and the culture dish was weighed. Pre-weighed ice-cold $50 \%$ sulfosalicylic acid was then added, and the plate was vigorously agitated to lyse the cells. Cell debris were mechanically detached using a cell scraper, and the homogenate was pipetted into an ice-cold 2-mL tube and stored at $-20^{\circ} \mathrm{C}$. Upon removal of cells, the culture dish was weighed again.

Viable live cells from 3 culture dishes were counted following 60 min of incubation with the ${ }^{13} \mathrm{C}$-enriched medium. Culture dishes were washed twice with warm PBS $\left(37^{\circ} \mathrm{C}\right)$ and each plate was weighed. Next, $1 \mathrm{~mL}$ of 0.05\% Trypsin EDTA (Sigma-Aldrich, St. Louis, MO) was added to the plate and incubated at $37^{\circ} \mathrm{C}$ for $5 \mathrm{~min}$. Upon visible detachment of cells, cells were removed in warm PBS and centrifuged for $5 \mathrm{~min}$ at $500 \times g$ at room temperature. The supernatant was decanted, and the pellet resuspended in PBS and centrifuged for another $5 \mathrm{~min}$ at $500 \times g$ at room temperature. The supernatant was then discarded. The pellet was resuspended in PBS, the weight was recorded, and $100 \mu \mathrm{L}$ of the suspensions was removed for cell counting using a hematocytometer and Trypan Blue solution, 0.4\% 
(\#K940, Amresco, Solon, OH). The remaining sample was centrifuged at $2,500 \times g$ at room temperature for 5 min, the supernatant decanted, and the cells were lysed by the addition of $1 \mathrm{~mL}$ of $2 \%$ SDS lysis buffer containing phosphatase (\#78426, Thermo Fisher Scientific) and protease (\#G6521, Promega, Madison, WI) inhibitors. The samples were constantly agitated for $30 \mathrm{~min}$ at $4^{\circ} \mathrm{C}$ and centrifuged for $1 \mathrm{~h}$ at $21,130 \times g$ at $4^{\circ} \mathrm{C}$ to remove insoluble material. The supernatant was stored at $-80^{\circ} \mathrm{C}$. Total protein in the lysate was determined using a bicinchoninic acid assay (Smith et al., 1985).

\section{AA Analyses}

The extracellular medium contents were gravimetrically weighed, deproteinized using $7 \%$ sulfosalicylic acid, and centrifuged at 16,000 $\times g$ for $15 \mathrm{~min}$ at $4^{\circ} \mathrm{C}$. The intracellular lysates plus sulfosalicylic acid (added when cells were harvested) were gravimetrically weighed and centrifuged at $16,000 \times g$ for $15 \mathrm{~min}$ at $4^{\circ} \mathrm{C}$. Supernatants of the extracellular medium and intracellular contents were gravimetrically weighed and combined with ${ }^{13} \mathrm{C}^{15} \mathrm{~N}$ universally labeled AA algae (97-99\% enriched, Cambridge Isotope Laboratories Inc., Tewksbury, MA). The intracellular content pel- let remaining following removal of the intracellular supernatant was gravimetrically weighed and combined with $250 \mu \mathrm{L}$ of a mixture containing ${ }^{13} \mathrm{C}^{15} \mathrm{~N}$ universally labeled AA algae (97-99\% enriched, Cambridge Isotope Laboratories Inc.) and $33.3 \mu \mathrm{L}$ of $6 \mathrm{M} \mathrm{HCl}$ containing $0.1 \%$ phenol per $\mathrm{mg}$ of pellet and hydrolyzed for 20 $\mathrm{h}$ at $97.5^{\circ} \mathrm{C}$. The acid hydrolysates from the extracellular and intracellular contents and the intracellular pellet were then desalted by ion chromatography (AG 50W-X8 resin, Bio-Rad, Hercules, CA), eluted with $2 \mathrm{~N}$ ammonia hydroxide into silanized glassware, and freeze-dried. Dried samples were resolubilized in 0.1 $N \mathrm{HCl}$ and derivatized in acetonitrile (J. T. Baker Inc., Phillipsburg, NJ) to form $N$-(tert-butyldimethyl) AA derivatives by incubation for $1 \mathrm{~h}$ at $70^{\circ} \mathrm{C}$ in $\mathrm{N}$ methyl- $N$-(tert-butyldimethylsilyl)-trifluoroacetamide (SELECTRA-SIL, UCT Inc., Bristol, PA). Amino acid derivatives were separated by GC (Trace GC Ultra, Thermo Fisher Scientific) and quantified by mass spectrometry (DSQII; Thermo Fisher Scientific) for ${ }^{15} \mathrm{~N},{ }^{13} \mathrm{C}$, and ${ }^{15} \mathrm{~N}^{13} \mathrm{C}$ enrichments of ions derived from each AA as previously described (Calder et al., 1999). Calibration curves for derivation of AA concentrations from the isotopic ratios were developed using the same labeled AA mixture spiked into the samples gravimetrically combined in varying ratios with an AA standard

Table 1. Amino acid concentrations and atom percent enrichment of the ${ }^{13} \mathrm{C}$ and ${ }^{15} \mathrm{~N}$ media before exposure to the cells

\begin{tabular}{|c|c|c|c|c|c|c|c|}
\hline \multirow[b]{3}{*}{$\mathrm{AA}$} & \multicolumn{7}{|c|}{ AA concentration and enrichment } \\
\hline & \multicolumn{4}{|c|}{${ }^{15} \mathrm{~N}$-enriched medium ${ }^{1}$} & \multicolumn{3}{|c|}{${ }^{13} \mathrm{C}$-enriched medium ${ }^{2}$} \\
\hline & \multicolumn{2}{|c|}{ Mean, $\mu M$} & $\mathrm{SD}, \mu M$ & $\mathrm{AP}^{3}$ & Mean, $\mu M$ & $\mathrm{SD}, \mu M$ & $\mathrm{AP}^{4}$ \\
\hline Ala & \multicolumn{2}{|l|}{324} & 0.6 & 55 & 307 & 5.9 & 54 \\
\hline Arg & \multicolumn{2}{|l|}{66} & 2.8 & 27 & 81 & 2.7 & 36 \\
\hline Asp & \multicolumn{2}{|l|}{50} & 1.1 & 84 & - & - & 99 \\
\hline Glu & \multicolumn{2}{|l|}{80} & 4.2 & 87 & 42 & 31.7 & 89 \\
\hline Gly & \multicolumn{2}{|l|}{375} & 5.3 & 29 & 322 & 2.1 & 10 \\
\hline Ile & \multicolumn{2}{|l|}{124} & 1.4 & 62 & 128 & 2.1 & 67 \\
\hline Leu & \multicolumn{2}{|l|}{187} & 2.2 & 68 & 202 & 3.4 & 68 \\
\hline Lys & \multicolumn{2}{|l|}{96} & 7.8 & 74 & 59 & 8.8 & 52 \\
\hline Met & \multicolumn{2}{|l|}{19} & 1.5 & 68 & 19 & 0.7 & 65 \\
\hline Phe & \multicolumn{2}{|l|}{70} & 3.5 & 73 & 59 & 6.2 & 99 \\
\hline Pro & \multicolumn{2}{|l|}{115} & 1.7 & 54 & 117 & 1.1 & 34 \\
\hline Ser & \multicolumn{2}{|l|}{190} & 17.5 & 37 & 139 & 8.8 & 32 \\
\hline Thr & \multicolumn{2}{|l|}{195} & 0.6 & 38 & 168 & 0.4 & 58 \\
\hline Tyr & \multicolumn{2}{|l|}{57} & 1.3 & 56 & 37 & 0.7 & 38 \\
\hline Val & \multicolumn{2}{|l|}{285} & 1.2 & 42 & 274 & 5.9 & 41 \\
\hline \multicolumn{8}{|c|}{$\begin{array}{l}{ }^{1} \text { Represents } 3 \text { samples. } \\
{ }^{2} \text { Represents } 3 \text { samples. }\end{array}$} \\
\hline \multirow{2}{*}{\multicolumn{2}{|c|}{${ }^{3} \mathrm{AP}:$ atom percent $=($}} & $\left({ }^{15} \mathrm{~N}\right.$ & & & & & \\
\hline & & $\left(\overline{{ }^{12} \mathrm{C}+{ }^{15} \mathrm{~N}}\right)$ & $x+100$ & & & & \\
\hline \multicolumn{2}{|c|}{${ }^{4} \mathrm{AP}:$ atom percent $=$} & $\left(\frac{{ }^{12} \mathrm{C}}{{ }^{12} \mathrm{C}+{ }^{13} \mathrm{C}}\right)$ & $\times 100$ & & & & \\
\hline
\end{tabular}


mix (\#AAS18, Sigma-Aldrich) plus L-Asn, L-Gln, LTrp, and L-Cys (Sigma-Aldrich).

\section{Model Development}

A dynamic system of differential equations and state variables was constructed to represent the transport and metabolism of a single AA within mammary epithelial cells. The described model was coded in $\mathrm{R}$ (version 3.3.2 and RStudio version 1.0.13; R Core Team, 2016). Primary-state variables were extracellular free AA $\left(Q_{x A A(i)}\right)$, intracellular free AA $\left(Q_{n A A(i)}\right)$, intracellular fast turnover protein-bound $\mathrm{AA}\left(Q_{t f A A(i)}\right)$, and intracellular slow turnover protein-bound AA $\left(Q_{t s A A(i)}\right)$ to represent the mass of ${ }^{12} \mathrm{C} \mathrm{AA},{ }^{13} \mathrm{C} \mathrm{AA}$, and ${ }^{15} \mathrm{~N} \mathrm{AA}$ resulting in 12 pools (Table 2). Rate constants and fluxes are described in Table 3. Mass $(Q)$, flux $(F)$, concentration $(C)$, and volume $(V)$ had units of nmol, $\mathrm{nmol} / \mathrm{min}, \mu M$, and $\mathrm{mL}$, respectively. Fast and slow turnover protein pools were used to represent the variable return of protein-bound label to the intracellular free pool with respect to time. Such a representation is an oversimplification, as each protein has its own respective protein turnover pool, and likely ranges from nanoseconds to years in time. Previously, it has been demonstrated that specification of fast and slow protein turnover pools is needed to adequately represent isotopic movement within the pool over 30 -h time periods (Hanigan et al., 2009; Estes et al., 2018).

The volume of the extracellular free AA pool $\left(V_{x}\right)$ was assumed to be $6 \mathrm{~mL}$ of medium, whereas the intracellular free AA pool $\left(V_{n}\right)$ and the intracellular proteinbound pool $\left(V_{t}\right)$ were calculated from measurements of their respective weights. Three separate measurements of intracellular volume were conducted: volume observed before removal, volume of cells removed, and volume of cells mechanically harvested. For our purposes, we designated the latter as the volume of the intracellular free AA pool because of the high variation in the other 2 measurements (Supplemental Table S3, https://doi.org/10.3168/jds.2020-18155).

Following removal of the free AA during deproteinization, the pellet was weighed, and it was weighed again before acid hydrolysis. The weight of the pellet was assumed to be the average of these 2 measurements and designated as the intracellular protein-bound pool. The mass of the extracellular free AA, intracellular free AA, and total-bound protein pools for the $i$ th AA $(i=$ Ala and Leu) were determined as

$$
Q_{x A A(i)}=V_{x(i)} \times C_{x A A(i)},
$$

$$
\begin{gathered}
Q_{n A A(i)}=V_{n(i)} \times C_{n A A(i)}, \\
Q_{t A A(i)}=V_{t(i)} \times C_{t A A(i)},
\end{gathered}
$$

where $Q_{x A A(i)}, Q_{n A A(i)}$, and $Q_{t A A(i)}$ represent the mass of extracellular AA, intracellular AA, and protein-bound AA of only ${ }^{12} \mathrm{C}$ AA. The volume and concentration of the intracellular and protein-bound pools were measured at each time point $(\mathrm{n}=24)$. The mass of each isotope was calculated from the pool size and isotopic enrichment:

$$
\begin{aligned}
& Q_{x A A(i)}^{13 \mathrm{C}}=Q_{x A A(i)} \times\left(\frac{C^{13}{ }_{x A A(i)}}{C^{12}{ }_{x A A(i)}}\right), \\
& Q_{x A A(i)}^{1{ }^{\mathrm{N}}}=Q_{x A A(i)} \times\left(\frac{N^{15}{ }_{x A A(i)}}{C^{12}{ }_{x A A(i)}}\right), \\
& Q_{n A A(i)}^{13 \mathrm{C}}=Q_{n A A(i)} \times\left(\frac{C^{13}{ }_{n A A(i)}}{C^{12}{ }_{n A A(i)}}\right), \\
& Q_{n A A(i)}^{15 \mathrm{~N}}=Q_{n A A(i)} \times\left(\frac{N^{15}{ }_{n A A(i)}}{C^{12}{ }_{n A A(i)}}\right), \\
& Q_{t A A(i)}^{13 \mathrm{C}}=Q_{t A A(i)} \times\left(\frac{C^{13}{ }_{t A A(i)}}{C^{12}{ }_{t A A(i)}}\right), \\
& Q_{t A A(i)}=Q_{t A A(i)} \times\left(\frac{N^{15}{ }_{t A A(i)}}{C^{12}{ }_{t A A(i)}}\right) .
\end{aligned}
$$

The initial proportion of the protein-bound pool resident in the fast and slow protein pools for each AA was estimated as that yielding the best model fit when varying the fast protein pool size by a fraction of 0.5 to $10 \%$ of the total protein-bound pool. The fast protein pool fraction was denoted $f_{t f}$ :

$$
\begin{gathered}
Q_{t f A A(i)}=Q_{t A A(i)} \times f_{t f(i)}, \\
Q_{t s A A(i)}=Q_{t A A(i)}-Q_{t f A A(i)},
\end{gathered}
$$


where $Q_{t A A(i)}, Q_{t f A A(i)}$, and $Q_{t s A A(i)}$ represent the total protein turnover, fast protein turnover, and slow protein turnover pools, respectively. The mass of each isotope for the fast protein pool was then calculated using the fast protein pool enrichment and the fast protein pool mass. The slow protein pool isotope mass was then calculated by subtraction:

$$
\begin{aligned}
& Q_{t f A A(i)}^{13} \mathrm{C}=Q_{t f A A(i)} \times\left(\frac{C^{13}{ }_{t f A A(i)}}{C^{12}{ }_{t f A A(i)}}\right), \\
& Q_{t s A A(i)}^{13} \mathrm{C}=Q_{t A A(i)}^{13}-Q_{t f A A(i)}^{13} \mathrm{C},
\end{aligned}
$$

Table 2. Description of initial estimates for volume, concentrations, pool sizes, and isotopic ratios for Ala and Leu

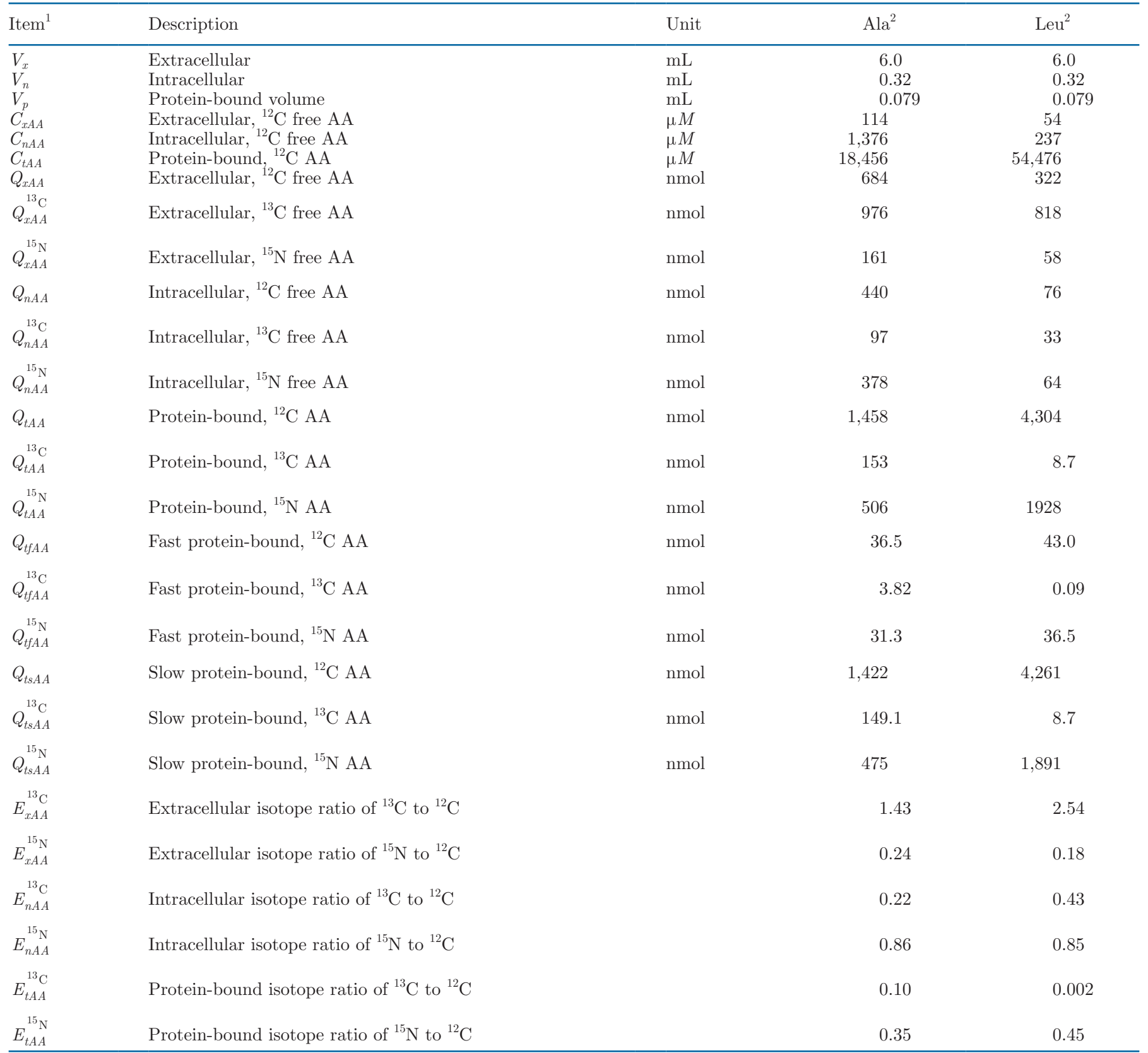

${ }^{1}$ Model abbreviations for volume $(V)$, concentration $(C)$, pools $(Q)$, and isotope ratios $(E)$.

${ }^{2}$ Alanine and leucine initial values represent the average of 6 plates of cells for volume and concentration, whereas mass of ${ }^{12} \mathrm{C}$, mass ${ }^{13} \mathrm{C}$, and ${ }^{15} \mathrm{~N}$ and isotope ratios represent the average of 3 plates of cells. 
Table 3. Descriptions, abbreviations, and units of rate constants and fluxes

\begin{tabular}{llc}
\hline Variable $^{1}$ & Description & Unit \\
\hline$k_{x A A n A A}$ & Rate constant for uptake & $\mathrm{min}$ \\
$k_{n A A x A A}$ & Rate constant for efflux & $\mathrm{min}$ \\
$k_{n A A t f A A}$ & Rate constant for fast turnover protein synthesis & $\mathrm{min}$ \\
$k_{n A A t s A A}$ & Rate constant for slow turnover protein synthesis & $\mathrm{min}$ \\
$k_{n A A n K A}$ & Rate constant for transamination & $\mathrm{min}$ \\
$k_{n A A O x}$ & Rate constant for oxidation & $\mathrm{min}$ \\
$f_{\text {synthesis }}$ & Fraction constant for NEAA synthesis & $\%$ \\
$f_{t f}$ & Fast turnover fraction of protein-bound pool & $\%$ \\
$f_{\text {carbon }}$ & Fraction of ${ }^{13} \mathrm{C}$ carbon used for reamination or synthesis & \\
$f_{n i t r o g e n}$ & Proportion of ${ }^{15}$ N nitrogen used for reamination or synthesis & $\mathrm{nmol} / \mathrm{min}$ \\
$F_{x A A n A A(i, j, k)}$ & Flux AA from extracellular to intracellular & $\mathrm{nmol} / \mathrm{min}$ \\
$F_{n A A x A A(i, j, k)}$ & Flux of AA from intracellular to extracellular & $\mathrm{nmol} / \mathrm{min}$ \\
$F_{n A A O x(i, j, k)}$ & Flux of AA from intracellular to oxidation & $\mathrm{nmol} / \mathrm{min}$ \\
$F_{n A A t f A A(i, j, k)}$ & Flux of AA from intracellular to fast protein synthesis & $\mathrm{nmol} / \mathrm{min}$ \\
$F_{t f A A n A A(i, j, k)}$ & Flux of AA from fast protein degradation to intracellular & $\mathrm{nmol} / \mathrm{min}$ \\
$F_{n A A n K A(i, j, k)}$ & Flux of AA from intracellular to transamination & $\mathrm{nmol} / \mathrm{min}$ \\
$F_{n K A n A A(i, j, k)}$ & Flux of AA from transamination to intracellular & $\mathrm{nmol} / \mathrm{min}$ \\
$F_{n S y n A A(i, j, k)}$ & Synthesis flux of AA to intracellular & \\
$F_{n K A n A A u(j, k)}$ & Flux of ${ }^{12} \mathrm{C}$ AA from transamination of ${ }^{13} \mathrm{C}$ AA to intracellular &
\end{tabular}

${ }^{1}$ Subscripts $i, j$, and $k$ represent the flux of ${ }^{12} \mathrm{C}-,{ }^{13} \mathrm{C}$-, or ${ }^{15} \mathrm{~N}$-enriched AA, respectively.

$$
\begin{gathered}
Q_{t f A A(i)}^{15} \mathrm{~N}=Q_{t f A A(i)} \times\left(\frac{N^{15}{ }_{t f A A(i)}}{C^{12}{ }_{t f A A(i)}}\right), \\
Q_{t s A A(i)}^{15} \mathrm{~N} \\
=Q_{t A A(i)}^{15} \mathrm{~N}-Q_{t f A A(i)}^{15} \mathrm{~N}
\end{gathered}
$$

Mass action kinetics were assumed for the fluxes among pools which included the following: AA influx and efflux between the extracellular medium and intracellular space; transamination, catabolism, or use for intracellular protein synthesis; and influx and efflux from the fast protein pool. Additionally, for Ala specifically, as an NEAA, intracellular Ala synthesis was considered. Flux descriptions are provided in Table 3. The differential equation describing the extracellular medium pool for the $i$ th AA ( $i=$ Ala and Leu) was

$$
\frac{\mathrm{d} Q_{x A A(i)}}{\mathrm{d} t}=F_{n A A x A A(i)}-F_{x A A n A A(i)},
$$

where $F_{n A A x A A(i)}$ represents efflux of AA from intracellular free pool to extracellular pool and $F_{x A A n A A(i)}$ the uptake of AA by the cell. The isotopic fluxes were calculated using the identical form as described above and for the remaining fluxes as follows:

$$
E_{a}=\frac{Q_{a^{*}}}{Q_{a}}
$$

$$
F_{a, b}^{*}=F_{a, b} \times E_{a},
$$

where $E_{a}, Q_{a^{*}}$, and $Q_{a}$ represents the isotope ratio, mass of the isotope, and mass of ${ }^{12} \mathrm{C}$ respective of a particular AA pool. A particular flux of a ${ }^{12} \mathrm{C}$ AA from pool A to $\mathrm{B}$ is represented as $F_{a, b}$ and the flux of the isotope AA from pool A to B is represented as $F^{*}{ }_{a, b}$. The AA influx was represented by the following for AA and the respective isotopes:

$$
F_{x A A n A A(i)}=k_{x A A n A A(i)} \times Q_{x A A(i)},
$$

where $k_{x A A n A A(i)}$ represents the mass action rate constant for uptake of AA by the cells. The AA efflux was

$$
F_{n A A x A A(i)}=k_{n A A x A A(i)} \times Q_{n A A(i)},
$$

where $k_{n A A x A A(i)}$ represents the mass action rate constant for AA efflux by the cells.

The differential for the intracellular free AA was also considered for the $i$ th AA and the respective isotopes:

$$
\begin{aligned}
& \frac{\mathrm{d} Q_{n A A(i)}}{\mathrm{d} t}=F_{x A A n A A(i)}+F_{t f A A n A A(i)}+F_{n K A n A A(i)}+F_{n S y n A A(i)} \\
& +F_{n K A n A A u(i)}-F_{n A A x A A(i)}-F_{n A A O x(i)}-F_{n A A t f A A(i)}-F_{n A A n K A(i)},
\end{aligned}
$$

where $F_{t f A A n A A(i)}$ represents the flux from degradation of the fast protein pool, $F_{n K A n A A(i)}$ represents reamination 
of keto-acids to form AA in the intracellular free AA pool, $F_{n S y n A A(i)}$ represents synthesis of AA, $F_{n A A O x(i)}$ represents oxidative loss, $F_{n A A t f A A(i)}$ represents AA incorporation into the fast turnover protein pool synthesis, $F_{n A A n K A(i)}$ represents deamination of loss, and $F_{n A A n K A(i)}$ represents deamination flux from the pool of carbon that was previously enriched with ${ }^{13} \mathrm{C}$ but underwent decarboxylation. Synthesis of fast and slow protein is described as

$$
\begin{gathered}
F_{n A A t f A A(i)}=k_{n A \operatorname{AtfAA}(i)} \times Q_{n A A(i)}, \\
F_{t f A A n A A(i)}=F_{n A A t f A A(i)}, \\
F_{n A A t s A A(i)}=k_{n A A t s A A(i)} \times Q_{n A A(i)}, \\
F_{t s A A n A A(i)}=F_{n A A t s A A(i)}, \\
F_{n A A n K A(i)}=k_{n A A n K A(i)} \times Q_{n A A(i)}, \\
F_{n K A n A A(i)}=F_{n A A n K A(i)},
\end{gathered}
$$

where $k_{n A A t f A A(i)}$ and $k_{n A A t s A A(i)}$ represent the mass action rate constants for protein synthesis. The mass of both protein pools was considered fixed; therefore, entry into each pool was set equal to the exit from each. The differential for the total protein-bound AA pool was the sum of the fast and slow pools:

$$
\frac{\mathrm{d} Q_{t A A(i)}}{\mathrm{d} t}=Q_{t f A A(i)}+Q_{t s A A(i)}
$$

The differential for the fast protein-bound pool was calculated and the pool size was assumed to be fixed:

$$
\frac{\mathrm{d} Q_{t f A A(i)}}{\mathrm{d} t}=F_{n A A t f A A(i)}-F_{t f A A n A A(i)} .
$$

The FME package of R (Soetaert and Petzoldt, 2010) was utilized to conduct local and global sensitivity, parameter identifiability, Markov chain Monte Carlo (MCMC) analysis, and model fitting as previously described (Wu et al., 2014). The time step was $15 \mathrm{~s}$ and Runge-Kutta 4th order was utilized for numerical integration. Initial intracellular pool sizes were set to the mean observed pool mass $(\mathrm{n}=6)$ from time
0 and $15 \mathrm{~s}$ (Table 2). Both time points were utilized to minimize measurement error associated with this model input. The respective enrichments and calculated isotope pool masses were calculated from the mean enrichment at time 0 for extracellular and intracellular free AA pools $(\mathrm{n}=3)$. The observed enrichment at time 0 for the intracellular free AA pool represented natural background abundance of ${ }^{13} \mathrm{C}$ AA and any ${ }^{13} \mathrm{C}$ AA medium contamination of the outfacing cellular membrane surface (Darmaun et al., 1988). The $Q_{x A A(i)}$, $Q_{n A A(i)}$, and $Q_{t A A(i)}$ were fitted to the measured mass of the respective ${ }^{12} \mathrm{C}$ AA, which represented 24,21 , and 21 observations, respectively. Additionally, these pools $Q_{x A A(i)}, Q_{n A A(i)}$, and $Q_{t A A(i)}$ were fitted to the measured mass of the respective ${ }^{13} \mathrm{C}$ and ${ }^{15} \mathrm{~N}$ AA, which represented an additional 24, 21, and 21 observations each, respectively.

The initial total protein pool mass was set equal to the mean across all samples $(\mathrm{n}=21)$, whereas the isotope enrichment was calculated from the average observed isotope ratio at time 0 and $15 \mathrm{~s}(\mathrm{n}=6)$. The fast protein turnover pool was initially set to $5 \%$ of the total protein pool and then varied between 0.5 and $10 \%$. The fast turnover pool size proportion resulting in the best log-likelihood function value was then selected. The initial enrichment of the fast protein turnover pool was set to equal the intracellular free AA pool, which is based on the assumption that the pool would have achieved isotopic equilibrium with the free AA pool over the $24 \mathrm{~h}$ period of ${ }^{15} \mathrm{~N}$-enriched medium incubation. The initial enrichment of the slow protein turnover pool was calculated by the difference from the mass of isotopes in the total protein and fast turnover protein pools.

Parameter bounds were set to a minimum of 0 and maximum of 1 for all parameters except AA synthesis, which was set to a minimum of 0 and maximum of 100 . Before parameter estimation, the linear dependence of the parameters was evaluated to determine collinearity using the collin function within the FME R package. A score of 1 indicates orthogonality between parameters (Brun et al., 2001). The maximum allowable score for a set of parameters was set to 15 for collinearity as higher scores indicate high collinearity and poor identifiability (Brun et al., 2001).

Model parameters were derived using the entire time series of measurements for pool size, volume, and enrichment using modCost and modFit functions within the FME package (Soetaert and Petzoldt, 2010). The model residuals were standardized based on the overall standard deviation of each respective variable when calculating residuals for model minimization: 


$$
\text { Residual }_{a}=\frac{\text { Predicted }_{a}-\text { Observed }_{a}}{S D_{a}}
$$

where Predicted $_{a}$, Observed , $_{a}$ and $S D_{a}$ are the modeled predicted, observed, and standard deviation of the observed data, respectively, of an individual variable within the model. Weighting of residuals is important in the situation in which some variables (i.e., isotope ratio) were measured with good precision versus others (i.e., AA mass) were measured with less precision (Soetaert and Petzoldt, 2010). Initial parameter estimates were derived using the Nelder-Mead algorithm, and final estimates using the initial estimates as starting values and the Marq algorithm, which in almost all cases resulted in identical parameter values. Parameter retention in the model was based on $P$-values $(P<$ $0.10)$, collinearity, and biological relevance.

Standard errors for fluxes and rate constants were derived by simulation to provide a more robust assessment of uncertainty versus standard errors derived during model parameter estimation (Efron and Tibshirani, 1986). The hierarchal structure of the data (i.e., time series, small sample size, high dimensionality, and desire for assessment of predictive power more than parameter sampling distribution) suggested a Bayesian approach over traditional bootstrapping from residuals for derivation of standard errors (Alfaro et al., 2003; Cronin et al., 2010; Efron, 2011). Uncertainty estimates were derived using MCMC with the delayed rejection and adaptive Metropolis algorithm (DRAM; Haario et al., 2006; Laine, 2008). For prior specification, the distribution of parameters $\theta$ were assumed to be Gaussian, parameters must be between 0 and 1 except for synthesis, which was 100, and within this range, a uniform noninformative probability was specified. A prior error variance must be specified for each parameter (Soetaert and Petzoldt, 2010). This prior variance was derived from the mean of the unweighted squared residuals from the model previously solved by maximum likelihood and the distribution was assumed to be normal. Additionally, the prior error variance is weighted based on the number of observations and a user specified value, which we set to 0.1 , which is quite low. For efficient burn-in, the initial parameter values were set to the maximum likelihood solution. The initial random walk-search-jumping distribution was specified using the variance matrix of the parameters when solved by maxima likelihood and scaled according to (Gelman et al., 2014) as follows:

$$
J\left(\theta^{*} \mid \theta^{t-1}\right)=N\left(\theta^{*} \mid \theta^{t-1}, c^{2} \Sigma\right)
$$

$$
c=\frac{2.4}{\sqrt{ } d} \times v,
$$

where $J, t, N, c, d$, and $v$ represent the target distribution kernel for the Metropolis algorithm, the function, normal distribution designation, the scaled covariance matrix, the number of parameters, and the unscaled covariance matrix. The proposal jumping distribution was set to update every 100 iterations. The burn-in length was set to one-half of the iterations $(n=5,000$; Gelman et al., 2014) and the total number of iterations for Markov chain sampling of the probability distribution was set to 10,000. The DRAM (Haario et al., 2006) was implemented if efficiency was low for the MCMC algorithm search and rejection process (Malve et al., 2007). The targeted acceptance rate by the Metropolis algorithm was $23 \%$ given 6 parameters that were being sampled at once (Gelman et al., 2014). Fine-tuning to achieve this acceptance rate was conducted by varying the jumping rule scale (i.e., number of iterations per jump) and implementation of DRAM. Upon completion of the MCMC analysis, the observed standard deviation of the parameter posterior was considered the standard error of the estimates (Erixon et al., 2003) with the assumption that the posterior distribution was normal and asymptotic. The parameter posterior from the MCMC analyses ( $\mathrm{n}=5,000$ rows) were then collected into a matrix and randomly sampled 1,000 times $(\mathrm{R}$ seed $=123)$. Using the randomly drawn parameters, the model was executed for each sample draw, and the distribution of the model predictions evaluated for the mean, standard deviation, and 95\% confidence intervals, thereby providing estimates of prediction power that accounts for parameter uncertainty, random error, and measurement error. Root mean squared errors as a percentage of the mean (RMSE) and mean squared errors partitioned into mean bias, slope bias, and dispersion were calculated using the residuals for the maximum likelihood and MCMC solutions (Bibby and Toutenberg, 1977). The concordance correlation coefficient (CCC) was also calculated to provide a dimensionless evaluation of precision and accuracy (Lin, 1989).

\section{RESULTS AND DISCUSSION}

The objective of this experiment was to develop a method to evaluate AA transport by assessment of AA influx, efflux, and intracellular metabolism. For demonstration purposes, one NEAA (Ala) and one EAA (Leu) were arbitrarily selected. This method is applicable to all AA that are enriched separately with ${ }^{13} \mathrm{C}$ and ${ }^{15} \mathrm{~N}$. 
The solved Ala and Leu models with fluxes, mass, and concentrations are provided in Figure 2.

\section{Model Development}

Development of a dynamic model to represent isotopic movement was necessary as isotopic equilibrium and steady-state across pools could not be assumed as has been done in previous transport kinetic experiments
(Biolo et al., 1995; Bequette et al., 2000; Miller et al., 2004). An advantage to our approach is the ability to delineate fluxes such as oxidation, transamination, synthesis, and degradation, all of which are difficult to define using steady-state modeling approaches (Biolo et al., 1995; Bequette et al., 2000). Fluxes mimicked biological expectations (Waterlow, 2006) and a previous described AA transport and metabolism model (Hanigan et al., 2009).

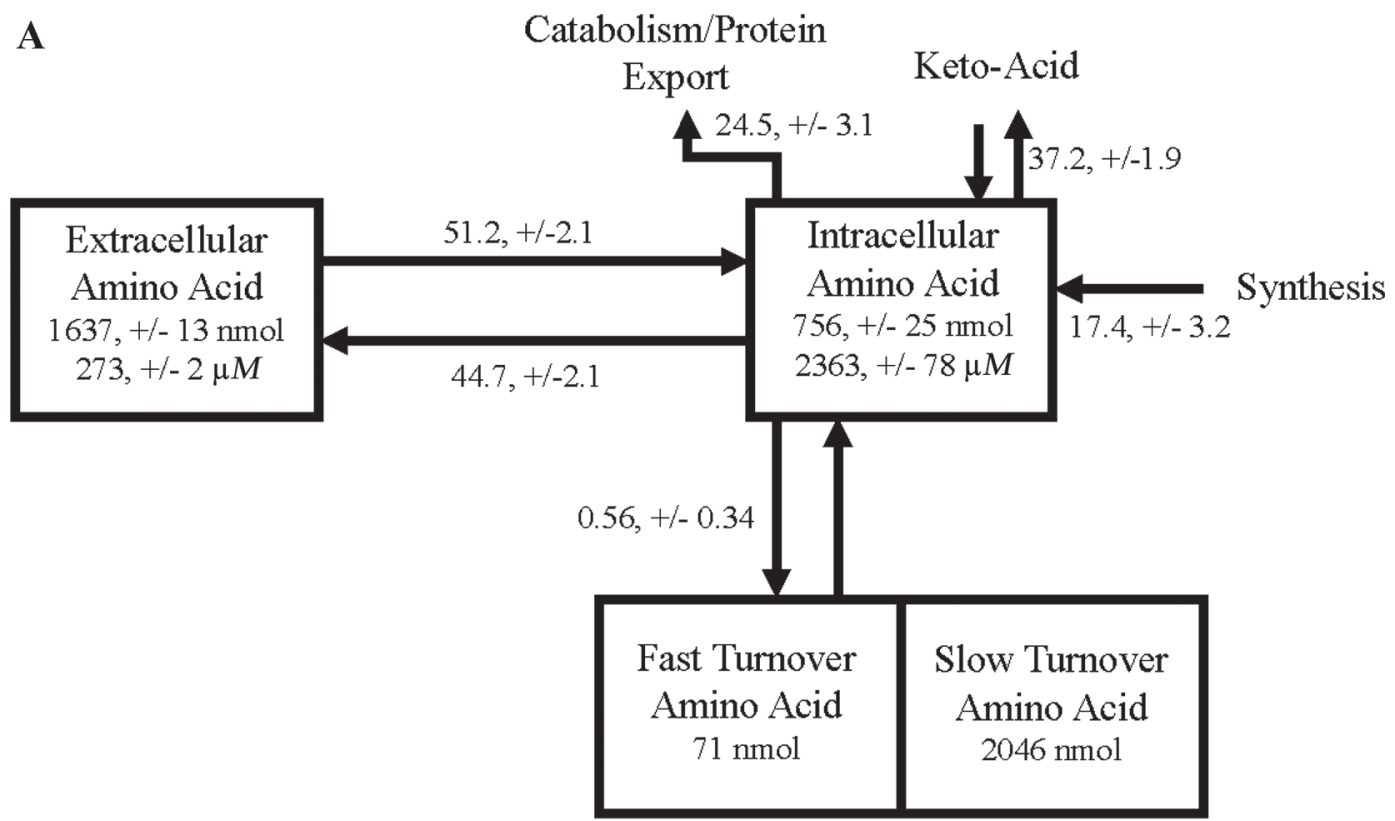

B

Catabolism/Protein

Export

Keto-Acid

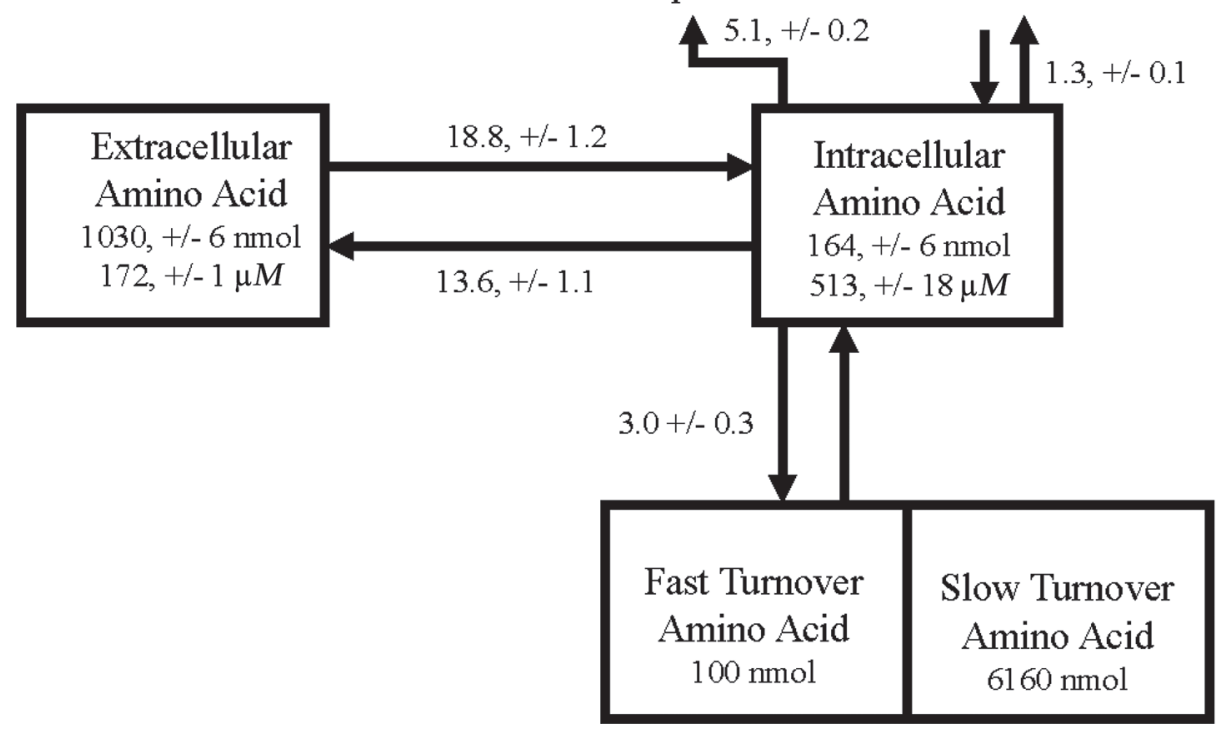

Figure 2. Alanine (A) and leucine (B) pool fitted pool masses (nmol), concentration $(\mu M)$, and fluxes (nmol/min). The extracellular AA concentrations were similar to in vivo blood plasma concentrations in lactating dairy cows. 
Table 4. Rate constant estimates derived by maximum likelihood and Markov chain Monte Carlo simulation

\begin{tabular}{|c|c|c|c|c|c|c|c|}
\hline \multirow[b]{2}{*}{ Parameter } & \multicolumn{4}{|c|}{$\mathrm{ML}^{1}$} & \multicolumn{2}{|c|}{$\mathrm{MCMC}^{2}$} & \multirow[b]{2}{*}{$\mathrm{CV} \%^{3}$} \\
\hline & Estimate & SE & $\mathrm{CV} \%^{3}$ & $P$-value & Estimate & $\mathrm{SE}$ & \\
\hline \multicolumn{8}{|l|}{ Alanine } \\
\hline$k_{x A A n A A}$ & 0.032 & 0.002 & 7.6 & $<0.001$ & 0.034 & 0.001 & 4.0 \\
\hline$k_{n A A x A A}$ & 0.053 & 0.004 & 8.1 & $<0.001$ & 0.065 & 0.004 & 6.1 \\
\hline$k_{n A A O x}$ & 0.029 & 0.004 & 12.8 & $<0.001$ & 0.034 & 0.005 & 14.3 \\
\hline$k_{n A A t f A A}$ & 0.001 & 0.000 & 31.8 & $<0.01$ & 0.001 & 0.001 & 42.1 \\
\hline$k_{n A A n K A}$ & 0.044 & 0.003 & 6.6 & $<0.001$ & 0.043 & 0.002 & 5.4 \\
\hline$f_{\text {synthesis }}$ & 8.914 & 1.662 & 18.6 & $<0.001$ & 8.699 & 1.845 & 21.2 \\
\hline $\begin{array}{l}\text { Jsynthesis } \\
f_{t f}\end{array}$ & 2.50 & - & - & - & 2.50 & - & - \\
\hline$f_{\text {carbon }}$ & 100 & - & - & - & 100 & - & - \\
\hline$f_{\text {nitrogen }}$ & 100 & - & - & - & 100 & - & - \\
\hline \multicolumn{8}{|l|}{ Leucine } \\
\hline$k_{x A A n A A}$ & 0.018 & 0.001 & 6.7 & $<0.001$ & 0.021 & 0.001 & 6.6 \\
\hline$k_{n A A x A A}$ & 0.087 & 0.007 & 8.3 & $<0.001$ & 0.099 & 0.006 & 6.4 \\
\hline$k_{n A A O x}$ & 0.033 & 0.002 & 5.4 & $<0.001$ & 0.030 & 0.002 & 6.4 \\
\hline$k_{n A A t f A A}$ & 0.019 & 0.002 & 12.0 & $<0.001$ & 0.016 & 0.004 & 22.0 \\
\hline$k_{n A A n K A}$ & 0.008 & 0.001 & 13.7 & $<0.001$ & 0.006 & 0.001 & 8.7 \\
\hline$f_{t f}$ & 1.00 & - & - & - & 1.00 & - & \\
\hline$f_{\text {carbon }}$ & - & - & - & - & - & - & \\
\hline$f_{\text {nitrogen }}$ & 100 & - & - & - & 100 & - & \\
\hline
\end{tabular}

Model parameters for uptake and efflux were well defined with standard errors that were less than $8 \%$ of the estimated values; whereas transamination, oxidation/protein export, turnover, and synthesis were derived with less confidence, standard errors were up to $32 \%$ of estimated values (Table 4). Although the correlations between uptake and efflux were high, 0.79 and 0.84 for Ala and Leu, respectively, the collinearity score indicated the parameters were identifiable (Brun et al., 2001; Supplemental Figures S1 and S2, https:/ /doi.org/10.3168/jds.2020-18155). All other parameter correlations were less than 0.63 for Leu, indicating the ability to uniquely derive the parameters (Supplemental Figure S2). More problematic, Ala rate constants for oxidation or protein export, incorporation into the fast turnover protein pool, and de novo synthesis were highly correlated, ranging from 0.88 to 0.90 (Supplemental Figure S1). However, the collinearity score was 10 , lower than the maximum of 15 recommended by Soetaert and Petzoldt (2010).

The maximum likelihood solution derived by FME reflected a deterministic model solution, whereas MCMC addresses the probability distribution of parameters (Wu et al., 2014). The uncertainty of predictions which is derived from posterior distributions is considered by some to be more important than derivation of a single set of parameters, as predictive power should account for parameter error, prediction random error, and nonrandom system error (Laine, 2008). Simulating the prior parameter values using MCMC resulted in different rate constant estimates in most cases (Table 4). The Bayesian fitting process searches through the posterior space, which we specified as uniform within specified lower and upper bounds and seeks solutions that represent improved fit values compared with the prior by the Metropolis algorithm. Given the high dimensionality of the model, high probability fit solutions usually represent a low proportion of specified prior search space. The observed mean of the posterior might reflect the high dimensionality of this problem, poor starting prior specification, and highly contoured nature of the solution space. Parameters with low correlations tended to have lower standard error compared with maximum likelihood, whereas highly correlated parameters had higher standard error with MCMC, which represents the uncertainty around these parameters. The posterior distribution and correlation parameter matrices are provided in Supplemental Figures S1 and S2. The Ala rate constants for synthesis, fast protein turnover, and oxidation are highly correlated (Supplemental Figure S1), which was reflected in high uncertainty in these rate constants and respective fluxes.

The oxidation rate constant was derived considering net loss of the AA as well as the labeled AA (i.e., ${ }^{13} \mathrm{C}$ and $\left.{ }^{15} \mathrm{~N}\right)$. In contrast, transamination rate constant considers no loss of the AA but only loss of ${ }^{13} \mathrm{C},{ }^{15} \mathrm{~N}$, 

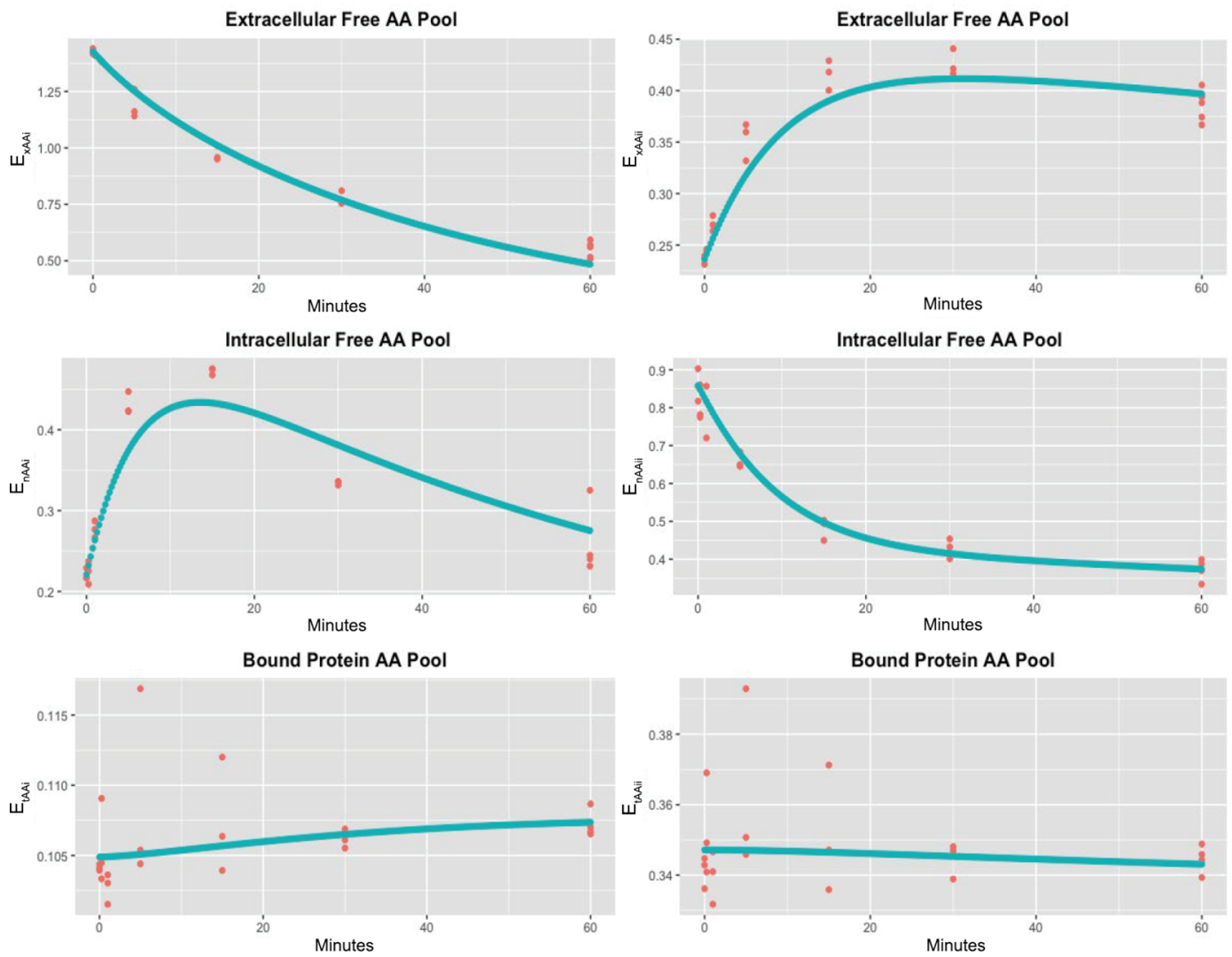

Figure 3. Alanine observed and predicted isotope mass ratios of ${ }^{13} \mathrm{C}$ to ${ }^{12} \mathrm{C}$ and ${ }^{15} \mathrm{~N}$ to ${ }^{12} \mathrm{C}$ within the medium, intracellular, and proteinbound pools. The y-axis labels refer to the following mass ratios: $E_{x A A i}=$ extracellular isotope ratio of ${ }^{13} \mathrm{C}$ to ${ }^{12} \mathrm{C} ; E_{x A A i i}=$ extracellular isotope ratio of ${ }^{15} \mathrm{~N}$ to ${ }^{12} \mathrm{C} ; E_{n A A i}=$ intracellular isotope ratio of ${ }^{13} \mathrm{C}$ to ${ }^{12} \mathrm{C} ; E_{n A A i i}=$ intracellular isotope ratio of ${ }^{15} \mathrm{~N}$ to ${ }^{12} \mathrm{C} ; E_{t A A i}=$ protein-bound isotope ratio of ${ }^{13} \mathrm{C}$ to ${ }^{12} \mathrm{C} ; E_{t A A i i}=$ protein-bound isotope ratio of ${ }^{15} \mathrm{~N}$ to ${ }^{12} \mathrm{C}$.

or both. For Ala, return of labeled $\mathrm{C}$ or $\mathrm{N}$ likely can occur and was specified using biological inference. The enrichment of these carbon and nitrogen precursor pools for reamination was set to the fast turnover pool enrichment as it improved model fit, reflecting a slight lag in equilibration with the intracellular free AA enrichment, and this lag was previously observed with casein enrichment (Hanigan et al., 2009).

The fraction of total protein that is fast protein constant $\left(f_{t f}\right)$ was iteratively varied between 0.5 and $10 \%$ and selection was based on best model fit. The greatest likelihood ratio was observed at 2.5 and $1 \%$ for Ala and Leu, respectively. At that setting, the fast protein pools for Ala and Leu reflected proteins that turned over within 128 and $34 \mathrm{~min}$, respectively. Hanigan et al. (2009) observed the fast protein proportion to be $6 \%$ for Leu when fitting to in vivo data from a 30-h infusion, which is slightly higher than our derived estimates.

Protein turnover has high heterogeneity across the several thousand proteins present in a cell; hence, simplification to a 2-pool model is a major assumption. A minimum of 2 protein pools (i.e., fast and slow) ap- pears to be necessary in these models to account for the changes in isotopic enrichment over time during the experiment. Intracellular free ${ }^{13} \mathrm{C}-\mathrm{Ala}$ enrichment started decreasing after 15 min despite extracellular enrichment still being much higher; hence, significant Ala entry to the intracellular pool other than from extracellular pool is occurring (Figure 3). In contrast, intracellular ${ }^{15} \mathrm{~N}$-Ala enrichment appears to reach equilibrium with extracellular ${ }^{15} \mathrm{~N}$ enrichment within $30 \mathrm{~min}$ (Figure 3). This implies that ${ }^{15} \mathrm{~N}$ enrichment of the fast turnover protein pool has apparently reached enrichment equilibrium. It is more difficult to determine if the slow turnover protein pool has reached equilibrium as the contribution to isotope dilution in the intracellular space is small, but this is highly unlikely based on the size of that pool, length of the experiment $(24 \mathrm{~h})$, and the turnover rate.

For Leu, de novo synthesis was not identifiable which was expected given its classification as an essential AA. Transamination to $\alpha$-keto-isocaproate was observed as indicated by positive estimates for $k_{n A A n K A}$. The return of labeled $\mathrm{N}$ during reamination improved model fit for 
Leu and hence was included, but a more encompassing model should account for labeled $\mathrm{N}$ across all AA, not just Leu. The decarboxylation of Leu is irreversible; hence, no carbon tracer should return during reamination and thus the return flux was set to zero.

For Ala, de novo synthesis was significant and different from zero, which reflects its importance for transporting N. The primary transamination product of Ala is pyruvate and this reaction is reversible. The return of labeled $\mathrm{N}$ and $\mathrm{C}$ improved model fit for Ala, which reflects use of carbon and nitrogen precursor pools that are enriched during reamination of Ala.

Model fit was evaluated by several methods to access the accuracy, precision, and robustness of the proposed model (Tables 5 and 6). For Ala and Leu, the RMSE was $12 \%$ or less for isotopic enrichment of the extracellular and intracellular free AA pools, indicating good fit relative to the observed values. The $\mathrm{CCC}$ values generally indicated model appropriateness in terms of accuracy and precision; however, the model poorly rep-

Table 5. Model fit statistics for Ala predictions

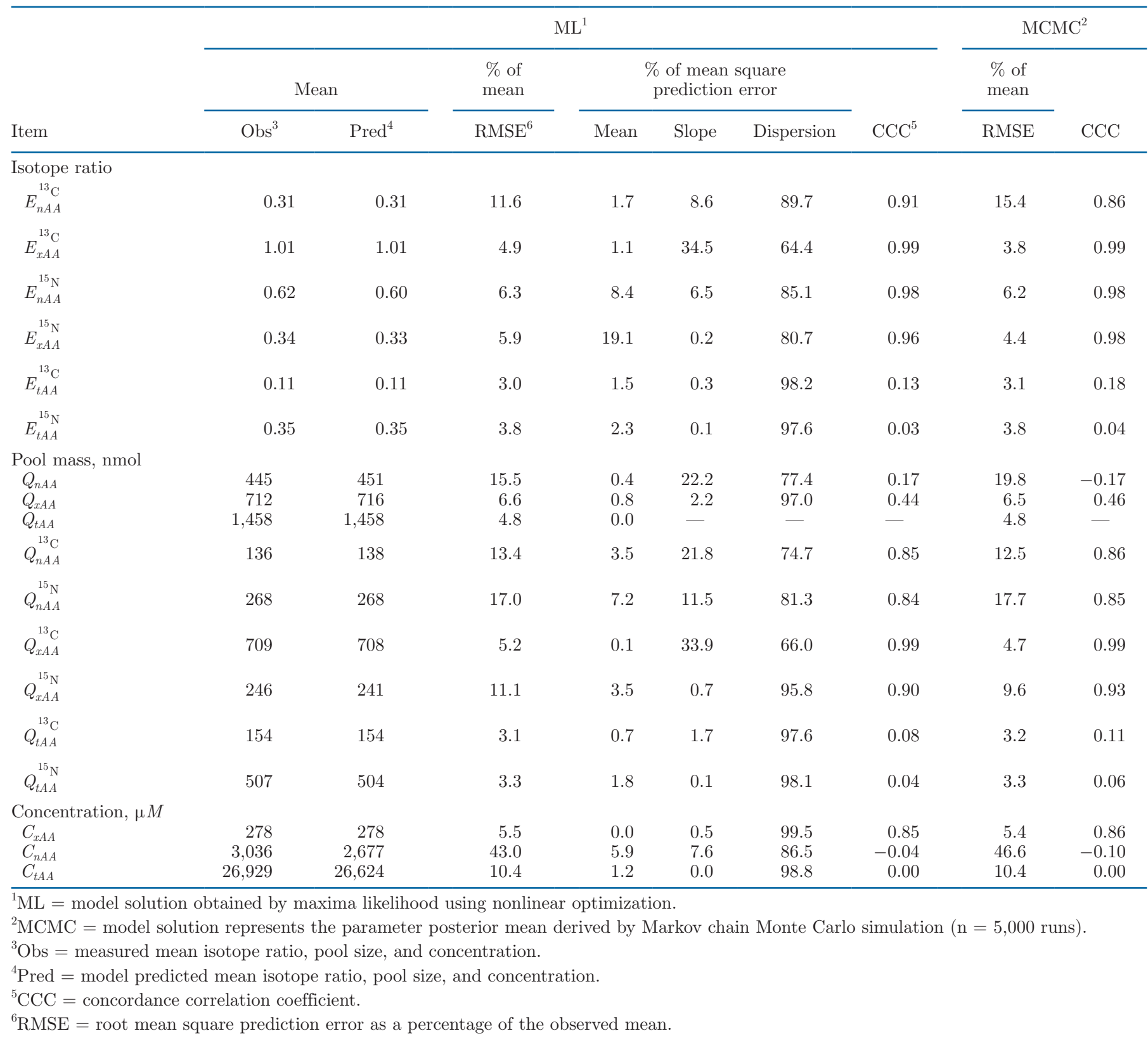


resented isotopic enrichment in the protein pool. This was likely because data variation was minimal and only one pool was characterized with inputs and outputs, the fast turnover pool. Evaluation of MCMC derived parameters indicated similar fit quality in terms of RMSE and CCC despite different parameter estimates. The fitting of isotopic enrichment of Phe in an in vivo assessment of AA transport resulted in an average RMSE of $28.1 \%$ (Hanigan et al., 2009), which is higher than the average RMSE of 5.9 and $11.6 \%$ for Ala and Leu isotopic enrichments in our study. Other AA transport models have not reported how well proposed parameters represent observed movement of AA (Biolo et al., 1995; Bequette et al., 2000; Miller et al., 2004).

\section{AA Concentration, Transport, and Metabolism}

The observed extracellular Ala and Leu concentrations were similar to in vivo, being within 3.7 and $6.1 \%$ of what is observed in the plasma of high-producing

Table 6. Model fit statistics for Leu predictions

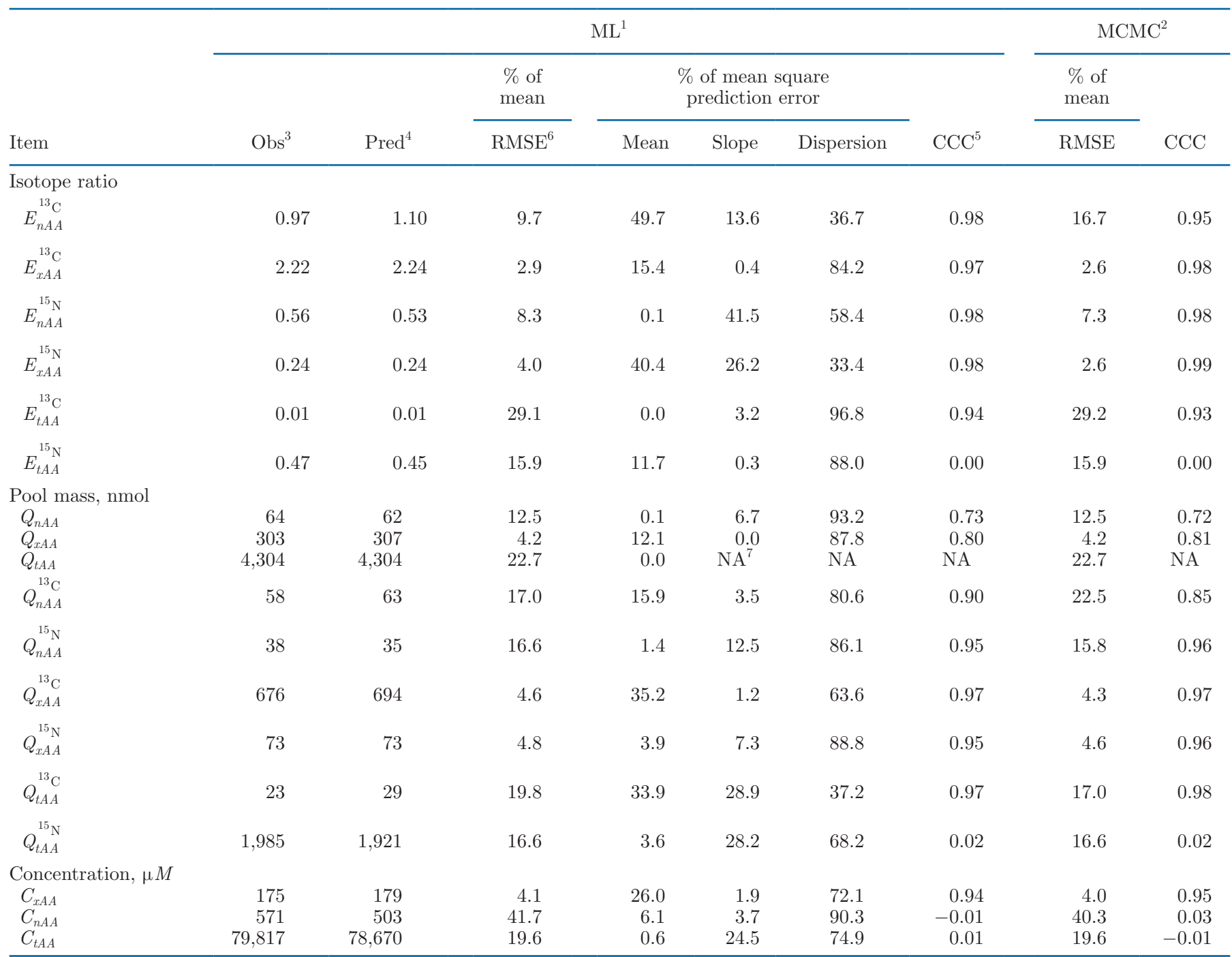

${ }^{1} \mathrm{ML}=$ model solution obtained by maxima likelihood using nonlinear optimization.

${ }^{2} \mathrm{MCMC}=$ model solution represents the parameter posterior mean derived by Markov chain Monte Carlo simulation ( $\mathrm{n}=5,000$ runs).

${ }^{3} \mathrm{Obs}=$ measured mean isotope ratio, pool size, and concentration .

${ }^{4}$ Pred $=$ model predicted mean isotope ratio, pool size, and concentration .

${ }^{5} \mathrm{CCC}=$ concordance correlation coefficient.

${ }^{6} \mathrm{RMSE}=$ root mean square prediction error as a percentage of the observed mean.

${ }^{7} \mathrm{NA}=$ not applicable. 
Table 7. Cellular flux predictions for Ala and Leu (nmol/min)

\begin{tabular}{|c|c|c|c|c|c|c|}
\hline Item & \multicolumn{2}{|c|}{ Ala } & $\mathrm{CV} \%^{3}$ & \multicolumn{2}{|c|}{ Leu } & $\mathrm{CV} \%^{3}$ \\
\hline Entry & 51.2 & 2.1 & 4.1 & 18.8 & 1.2 & 6.2 \\
\hline Net uptake & 6.4 & 0.3 & 5.1 & 5.2 & 0.1 & 2.8 \\
\hline Fast turnover protein synthesis & 0.6 & 0.3 & 61.8 & 3.0 & 0.3 & 9.6 \\
\hline Fast turnover protein degradation & 0.6 & 0.4 & 60.0 & 2.4 & 0.3 & 11.1 \\
\hline Extracellular turnover of free AA, $\% \mathrm{~h}$ & 164.0 & & & 79.2 & & \\
\hline Intracellular turnover of free AA, $\% \mathrm{~h}$ & 548.7 & & & 776.3 & & \\
\hline Fast turnover protein-bound $\mathrm{AA}, \% \mathrm{~h}$ & 47.0 & & & 179.1 & & \\
\hline
\end{tabular}

${ }^{1}$ Average flux over $60 \mathrm{~min}$ using rate constants derived by maxima likelihood.

${ }^{2} \mathrm{SE}$ represents the SD of 1,000 simulations randomly drawing parameters from the respective parameter posterior.

${ }^{3} \mathrm{CV} \%=$ SE divided by mean flux value.

dairy cows (Swanepoel et al., 2016; Table 1; Supplemental Table S1, https://doi.org/10.3168/jds.2020 -18155). Intracellular concentrations were 10.9 and 3.3-fold higher than extracellular for Ala and Leu, respectively, indicating a steep concentration gradient (Tables 5 and 6). The vast majority of AA transport is mediated by active transport; hence, the observation of a significant gradient supports this theory. In human muscle, Ala and Leu concentrations were found to be 5.5- and 1.5-fold greater in the intracellular space than in the extracellular space (Miller et al., 2004). In lactating dairy goats, intracellular Leu concentrations were 3.3-fold higher than extracellular, exactly what we observed (Hanigan et al., 2009). The much higher ratio of Ala relative to Leu likely reflects de novo synthesis, importance for providing trans-stimulation to drive system $\mathrm{L}$ transport, and its role as a $\mathrm{N}$ carrier and mediator (Bender, 2012). Also, the ratio of Ala to Leu changed dramatically between extracellular and intracellular, 1.6 to 5.3; hence, assumptions that blood AA profiles match the intracellular AA profile are incorrect. The intracellular profile represents intracellular metabolism and the dynamics of AA transport, which greatly modifies the blood AA profile.

Within the protein-bound pool, our results indicate Leu was present 3 -fold higher than Ala, which is somewhat unexpected given previous estimates of cattle (Wu, 2013) and mammary tissue AA profiles (Shennan et al., 1997; Tables 5 and 6). However, neither of these studies specifically examined bovine epithelial cell protein.

The prediction of AA fluxes (i.e., influx, efflux, and metabolism) represents the primary objective of this method (Table 7). Standard errors based on the MCMC simulation indicated that entry, exit, and net uptake of Ala and Leu from the cell was predicted with
$8.1 \%$ error or less (Table 7). Metabolic fluxes were predicted with slightly less confidence with the exception of the fast turnover protein synthesis, which had a CV of $61.8 \%$. The high turnover rates of the Ala and Leu extracellular (i.e., 37 and $76 \mathrm{~min}$ ) and intracellular free pools (i.e., 11 and 8 min) illustrate just how rapid exchange is and the inherent flexibility present to meet needs for protein synthesis. Extracellular Ala turnover was approximately twice as high as Leu, which likely reflects its role in driving system $\mathrm{L}$ transport, and the high capacity of system ASC, a sodium-dependent transporter, for taking up Ala (Bender, 2012; Bröer and Bröer, 2017). In lactating goats, approximately $55 \%$ of Leu that entered mammary tissue was released, which is lower than our observation of $72 \%$. In human muscle, $104 \%$ of Ala and Leu entering muscle tissue was effluxed (Miller et al., 2004). An early study in human muscle observed that $136 \%$ of Ala that entered muscle cells was released (Biolo et al., 1995). The observed fluxes illustrate the very rapid exchange of Ala and Leu across the cell membrane that previous studies with arterial-venous difference measurements (Lapierre et al., 2012) are missing.

Whether this high level of exchange occurs in lactating dairy cows is unknown, but if confirmed, might provide a strong mechanism for matching intracellular specific AA needs in the face of daily variations in AA supply. High AA exchange rates do occur in the udder of lactating goats, with an estimated 69, 55, 53, and $69 \%$ of uptake of Phe, Leu, Met, and Val being effluxed (Hanigan et al., 2009). Competitive inhibition of transport systems is well documented (Baumrucker, 1984; Hurley et al., 2000; Jackson et al., 2000); hence, whether the AA profile or concentration affects exchange of intracellular AA by competing for transporters warrants investigation. Is there a specific profile and 
concentration of AA that best optimizes transport (e.g., minimizing competitive inhibition, driving exchange by increasing NEAA) to meet the needs of intracellular protein synthesis? These questions will require further research in this area.

The turnover rates of the fast protein pool were quite rapid and likely reflect proteins with very short half-lives (i.e., $30 \mathrm{~min}$ ). The finding that Leu turnover was nearly 4 times faster than Ala turnover confirms a previous study of high turnover rates of branched-chain AA (Hanigan et al., 2009), which reflects that proteins with high turnover rates are more highly enriched in branched-chain AA. In that previous study, the Leu fast turnover rate was $151 \% \mathrm{~h}$, which is close to what we observed (i.e., 179\% h; Hanigan et al., 2009).

\section{Medium AA Concentrations and Enrichment}

Extracellular AA profile and concentrations were set to mimic plasma concentrations of lactating dairy cows (Swanepoel et al., 2016). Evaluation of AA transport should consider all AA (Christensen, 1990). Transporter specificity is broad as AA can use multiple transporters. Competition for transporter sites and the synchrony of exchange driven transport ensures considerable interactions among AA with respect to transport. Transport kinetic experiments therefore should not be conducted using standard cell culture medium (i.e., Dulbecco's modified Eagle medium); they should be conducted using medium that more closely replicates in vivo AA concentrations and profile.

The measured AA concentration and profile of the ${ }^{13} \mathrm{C}$ - and ${ }^{15} \mathrm{~N}$-enriched experimental media were similar for most AA to the targeted concentrations (Table 1; Supplemental Table S1, https://doi.org/10.3168/jds .2020-18155). The discrepancies in some observed AA concentrations versus target concentrations stems from the inability to simultaneously achieve desired concentrations and enrichments and error. For Asp, Glu, and Phe, the concentrations in the algae $\left({ }^{13} \mathrm{C}\right.$-enriched and ${ }^{15} \mathrm{~N}$-enriched) and the amount of algae needed to achieve adequate enrichment of the other AA resulted in slightly higher concentrations in the experimental medium, particularly for Asp. For these AA, no ${ }^{12} \mathrm{C}$ was added to the medium, which resulted in very low assayed abundance of ${ }^{12} \mathrm{C}$ for concentration determination, particularly for Phe. Three forms of enriched algae from Cambridge Isotope Laboratories were used for isotope enrichment, but the AA concentration and profile of these algae were unknown before analysis. The observed differences in assayed AA concentrations between HPLC and isotope dilution measurements likely reflect methodology differences and sample size, with the latter method having 9 replicates (Supplemental Table S2, https://doi.org/10.3168/jds.2020-18155). Our results indicate in some cases $>25 \%$ differences in $\mathrm{CP}$ concentration and AA profile between the enriched algae, which might reflect different growing, harvesting, or acid hydrolysis recovery conditions of the enriched algae for each specific production lot. Future research should determine the isotope-enriched algae AA content as it may differ from the reported values herein.

Four AA were present in very low to immeasurable concentrations in the respective algae used, which is related to algae composition and loss during acid hydrolysis (i.e., Trp, Cys, Asn, and Gln). In our experiment, these $4 \mathrm{AA}$ as well as His were added entirely in ${ }^{12} \mathrm{C}$ form to meet their targeted concentration in the ${ }^{15} \mathrm{~N}$ medium. In the ${ }^{13} \mathrm{C}$ medium, individual ${ }^{15} \mathrm{~N}$-enriched Asn, Cys, Gln, and His were added to achieve isotope enrichment; however, only enrichment of Gln and His was observed, indicating the Asn and Cys amount were either too low or lost during the derivatization process. The AA concentration for AA not enriched in the ${ }^{13} \mathrm{C}^{15} \mathrm{~N}$ algae that were added as an external tracer were not determined as the addition of ${ }^{15} \mathrm{~N}$ or ${ }^{13} \mathrm{C}$ tracers were not possible because cell and medium contents already contained these isotopes. Hence, this method is not applicable for 5 of the $20 \mathrm{AA}$.

Atom percent excess (APE) values were not used because reliance on only 3 background samples and integration of low abundance ions in a background sample on quadrupole MS increase variance of these measurements. Given that we measured enrichment in all pools at time zero, the enrichment change over time as an input for the model yields the same answer as using APE. The resulting ${ }^{15} \mathrm{~N}$ experimental medium achieved APE values of 42.1 and 52.9 for Ala and Leu, indicating significant enrichment over background (Supplemental Table S4, https://doi.org/10.3168/jds.2020-18155). For the ${ }^{13} \mathrm{C}$ medium, APE values were 46.3 and 68.3 for Ala and Leu, respectively (Supplemental Table S4). Interestingly, ${ }^{13} \mathrm{C}$ enrichment of cellular intracellular free AA but not protein-bound AA at time zero was different than the background samples, which indicates extracellular attachment of AA (Supplemental Table S4). Extracellular AA attachment was expected, underscoring the importance of time zero measurements (Darmaun et al., 1988).

Cells were incubated for $24 \mathrm{~h}$ with ${ }^{15} \mathrm{~N}$-enriched medium in an attempt to achieve near stable enrichment of intracellular free AA and the fast turnover proteinbound pool of AA (Supplemental Table S5, https://doi .org/10.3168/jds.2020-18155). Enrichment assessment of Ala and Leu in the medium over time indicates that within $16 \mathrm{~h}$, near steady state was achieved within 

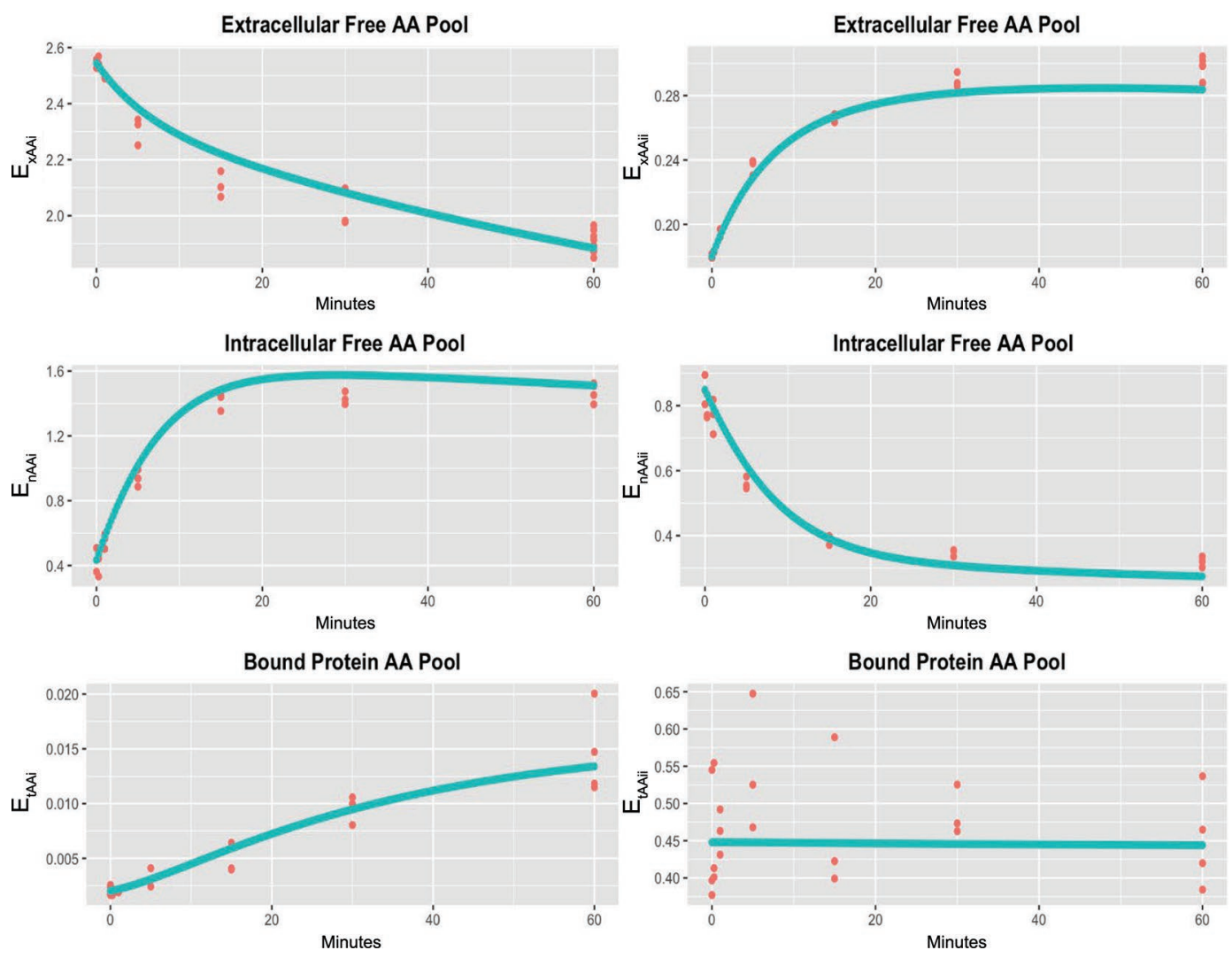

Figure 4. Leucine observed and predicted isotope mass ratios of ${ }^{13} \mathrm{C}$ to ${ }^{12} \mathrm{C}$ and ${ }^{15} \mathrm{~N}$ to ${ }^{12} \mathrm{C}$ within the medium, intracellular, and proteinbound pools. The y-axis labels refer to the following mass ratios: $E_{x A A i}=$ extracellular isotope ratio of ${ }^{13} \mathrm{C}$ to ${ }^{12} \mathrm{C} ; E_{x A A i i}=$ extracellular isotope ratio of ${ }^{15} \mathrm{~N}$ to ${ }^{12} \mathrm{C} ; E_{n A A i}=$ intracellular isotope ratio of ${ }^{13} \mathrm{C}$ to ${ }^{12} \mathrm{C} ; E_{n A A i i}=$ intracellular isotope ratio of ${ }^{15} \mathrm{~N}$ to ${ }^{12} \mathrm{C} ; E_{t A A i}=$ protein-bound isotope ratio of ${ }^{13} \mathrm{C}$ to ${ }^{12} \mathrm{C} ; E_{t A A i i}=$ protein-bound isotope ratio of ${ }^{15} \mathrm{~N}$ to ${ }^{12} \mathrm{C}$.

the medium. Additionally, the observed turnover rate for the fast turnover protein pool indicates complete turnover within 128 and 34 min for Ala and Leu, respectively (Table 7). Incubation for $24 \mathrm{~h}$ thus achieved a stable plateau within the fast turnover protein and intracellular free AA pools.

A shortcoming of this method was the inability to solve for a slow turnover protein rate constant, which was reflected by high collinearity and high standard errors when attempting to derive this rate constant (data not shown). A longer-term incubation of particularly the ${ }^{13} \mathrm{C}$ tracer would greatly enhance our ability to derive a slow turnover rate constant. Isotopic equilibrium of medium, intracellular, and fast protein pools appeared to be reached within $60 \mathrm{~min}$ for Ala and Leu ${ }^{15} \mathrm{~N}$ enrichment (Figures 3 and 4). In contrast, ${ }^{13} \mathrm{C}$ stable plateau enrichment was not achieved and likely reflected intracellular dynamics of protein turnover, particularly the Ala fast pool, still increasing in enrichment (Figures 3). However, this was apparently inadequate to define the turnover rate of the slow protein pool. This problem should be resolvable by the addition of one or more sampling time points with much longer exposure to the ${ }^{13} \mathrm{C}$-labeled medium to allow more time for accumulation of label in the slow turnover pool.

\section{CONCLUSIONS}

We have demonstrated a method to evaluate AA transport and metabolism in mammary epithelial cells. This method provides estimates of transport for multiple AA $(\mathrm{n}=15)$, which can be modified to measure all 20 AA. The dynamic 12-pool model demonstrated adequate fit and prediction power for all flux assessments except for the slow protein turnover rate given the data collected. In general, observed concentration gradients and fluxes matched biological expectations, suggesting validity of the method and model. The observed fluxes illustrate the rapid exchange of Ala and Leu across the cell membrane. This exchange likely provides harmonization and buffering capacity of extracellular supplies of AA to ensure that cellular AA supply and use for protein translation are aligned. Application of this method to varying levels or profiles of AA supply 
should provide more insight into AA transport activity and regulation and to the role it plays in regulating milk protein synthesis.

\section{ACKNOWLEDGMENTS}

This project was supported by funding from Perdue AgriBusiness LLC (Salisbury, MD). The authors are grateful for the labor and mentorship of Tara Pilonero and Xinbei Huang (both of Virginia Tech Dairy Science Department, Blacksburg, VA) with this experiment. The authors have not stated any conflicts of interest.

\section{REFERENCES}

Alfaro, M. E., S. Zoller, and F. Lutzoni. 2003. Bayes or bootstrap? A simulation study comparing the performance of Bayesian Markov chain Monte Carlo sampling and bootstrapping in assessing phylogenetic confidence. Mol. Biol. Evol. 20:255-266. https://doi.org/ 10.1093/molbev $/ \mathrm{msg} 028$.

Arriola Apelo, S. I., J. R. Knapp, and M. D. Hanigan. 2014. Invited review: Current representation and future trends of predicting amino acid utilization in the lactating dairy cow. J. Dairy Sci. 97:4000-4017. https://doi.org/10.3168/jds.2013-7392.

Baumrucker, C. R. 1984. Cationic amino acid transport by bovine mammary tissue. J. Dairy Sci. 67:2500-2506. https://doi.org/10 .3168/jds.S0022-0302(84)81606-9.

Bender, D. A. 2012. Amino Acid Metabolism. 3rd ed. John Wiley \& Sons Ltd., Hoboken, NJ.

Bequette, B. J., M. D. Hanigan, A. G. Calder, C. K. Reynolds, G. E. Lobley, and J. C. MacRae. 2000. Amino acid exchange by the mammary gland of lactating goats when histidine limits milk production. J. Dairy Sci. 83:765-775. https://doi.org/10.3168/jds .S0022-0302(00)74939-3.

Bibby, J., and H. Toutenberg. 1977. Prediction and Improved Estimation in Linear Models. Wiley, Chichester, UK.

Biolo, G., R. Y. Fleming, S. P. Maggi, and R. R. Wolfe. 1995. Transmembrane transport and intracellular kinetics of amino acids in human skeletal muscle. Am. J. Physiol. 268:E75-E84. https://doi .org/10.1152/ajpendo.1995.268.1.E75.

Bröer, S., and A. Bröer. 2017. Amino acid homeostasis and signalling in mammalian cells and organisms. Biochem. J. 474:1935-1963. https://doi.org/10.1042/BCJ20160822.

Brun, R., P. Reichert, and H. R. Kunsch. 2001. Practical identifiability analysis of large environmental simulation models. Water Resour. Res. 37:1015-1030. https://doi.org/10.1029/2000WR900350.

Calder, A. G., K. E. Garden, S. E. Anderson, and G. E. Lobley. 1999. Quantitation of blood and plasma amino acids using isotope dilution electron impact gas chromatography/mass spectrometry with U-(13)C amino acids as internal standards. Rapid Commun. Mass Spectrom. 13:2080-2083. https://doi.org/10.1002/(SICI)1097 -0231(19991115)13:21<2080::AID-RCM755>3.0.CO;2-O.

Cant, J. P., J. J. M. Kim, S. R. L. Cieslar, and J. Doelman. 2018. Symposium review: Amino acid uptake by the mammary glands: where does the control lie? J. Dairy Sci. 101:5655-5666. https:// doi.org/10.3168/jds.2017-13844.

Christensen, H. N. 1990. Role of amino acid transport and countertransport in nutrition and metabolism. Physiol. Rev. 70:43-77. https://doi.org/10.1152/physrev.1990.70.1.43.

Cronin, B., I. H. Stevenson, M. Sur, and K. P. Kording. 2010. Hierarchical Bayesian modeling and Markov chain Monte Carlo sampling for tuning-curve analysis. J. Neurophysiol. 103:591-602. https:// doi.org/10.1152/jn.00379.2009.

Darmaun, D., D. E. Matthews, J. F. Desjeux, and D. M. Bier. 1988. Glutamine and glutamate nitrogen exchangeable pools in cultured fibroblasts: A stable isotope study. J. Cell. Physiol. 134:143-148. https://doi.org/10.1002/jcp.1041340118.

Efron, B. 2011. The bootstrap and Markov-chain Monte Carlo. J. Biopharm. Stat. 21:1052-1062. https://doi.org/10.1080/10543406 .2011.607736.

Efron, B., and R. Tibshirani. 1986. Bootstrap methods for standard errors, confidence intervals, and other measures of statistical accuracy. Stat. Sci. 1:54-75. https://doi.org/10.1214/ss/1177013815.

Erixon, P., B. Svennblad, T. Britton, and B. Oxelman. 2003. Reliability of Bayesian posterior probabilities and bootstrap frequencies in phylogenetics. Syst. Biol. 52:665-673. https://doi.org/10.1080/ 10635150390235485.

Estes, K. A., R. R. White, P. S. Yoder, T. Pilonero, H. Schramm, H. Lapierre, and M. D. Hanigan. 2018. An in vivo stable isotopebased approach for assessment of absorbed amino acids from individual feed ingredients within complete diets. J. Dairy Sci. 101:7040-7060. https://doi.org/10.3168/jds.2017-13447.

Gelman, A., J. Carlin, H. Stern, D. Dunson, A. Vehtari, and D. Rubin. 2014. Bayesian Data Analysis. 3rd ed. Chapman \& Hall/CRC, Boca Raton, FL.

Haario, H., M. Laine, A. Mira, and E. Saksman. 2006. DRAM: Efficient adaptive MCMC. Stat. Comput. 16:339-354. https://doi .org/10.1007/s11222-006-9438-0.

Hanigan, M. D., C. C. Calvert, E. J. DePeters, B. L. Reis, and R. L. Baldwin. 1992. Kinetics of amino acid extraction by lactating mammary glands in control and sometribove-treated Holstein cows. J. Dairy Sci. 75:161-173. https://doi.org/10.3168/jds.S0022 $-0302(92) 77750-9$.

Hanigan, M. D., J. France, S. J. Mabjeesh, W. C. McNabb, and B. J. Bequette. 2009. High rates of mammary tissue protein turnover in lactating goats are energetically costly. J. Nutr. 139:1118-1127. https://doi.org/10.3945/jn.108.103002.

Hanigan, M. D., C. K. Reynolds, D. J. Humphries, B. Lupoli, and J. D. Sutton. 2004. A model of net amino acid absorption and utilization by the portal-drained viscera of the lactating dairy cow. J. Dairy Sci. 87:4247-4268. https://doi.org/10.3168/jds.S0022 $-0302(04) 73570-5$.

Hristov, A. N., W. J. Price, and B. Shafii. 2004. A meta-analysis examining the relationship among dietary factors, dry matter intake, and milk and milk protein yield in dairy cows. J. Dairy Sci 87:2184-2196. https://doi.org/10.3168/jds.S0022-0302(04)70039 -9 .

Hurley, W. L., H. Wang, J. M. Bryson, and D. B. Shennan. 2000. Lysine uptake by mammary gland tissue from lactating sows. J. Anim. Sci. 78:391-395. https://doi.org/10.2527/2000.782391x.

Jackson, S. C., J. M. Bryson, H. Wang, and W. L. Hurley. 2000. Cellular uptake of valine by lactating porcine mammary tissue. J. Anim. Sci. 78:2927-2932. https://doi.org/10.2527/2000.78112927x.

Laine, M. 2008. Adaptive MCMC Methods with Applications in Environmental and Geophysical Models. Finnish Meteorological Institute Contributions.

Lapierre, H., G. E. Lobley, L. Doepel, G. Raggio, H. Rulquin, and S. Lemosquet. 2012. Triennial lactation symposium: Mammary metabolism of amino acids in dairy cows. J. Anim. Sci. 90:1708-1721. https://doi.org/10.2527/jas.2011-4645.

Lin, L. I. 1989. A concordance correlation coefficient to evaluate reproducibility. Biometrics 45:255-268. https://doi.org/10.2307/ 2532051.

Malve, O., M. Laine, H. Haario, T. Kirkkala, and J. Sarvala. 2007. Bayesian modelling of algal mass occurrences - using adaptive MCMC methods with a lake water quality model. Environ. Model. Softw. 22:966-977. https://doi.org/10.1016/j.envsoft.2006.06.016.

Miller, S., D. Chinkes, D. A. MacLean, D. Gore, and R. R. Wolfe. 2004. In vivo muscle amino acid transport involves two distinct processes. Am. J. Physiol. Endocrinol. Metab. 287:E136-E141. https://doi.org/10.1152/ajpendo.00092.2004.

R Core Team. 2016. A Language and Environment for Statistical Computing. R Foundation for Statistical Computing, Vienna, Austria.

Shennan, D. B., and C. A. Boyd. 2014. The functional and molecular entities underlying amino acid and peptide transport by the mam- 
mary gland under different physiological and pathological conditions. J. Mammary Gland Biol. Neoplasia 19:19-33. https://doi .org/10.1007/s10911-013-9305-5.

Smith, P. K., R. I. Krohn, G. T. Hermanson, A. K. Mallia, F. H. Gartner, M. D. Provenzano, E. K. Fujimoto, N. M. Goeke, B. J. Olson, and D. C. Klenk. 1985. Measurement of protein using bicinchoninic acid. Anal. Biochem. 150:76-85. https://doi.org/10 .1016/0003-2697(85)90442-7.

Soetaert, K., and T. Petzoldt. 2010. Inverse Modellin, Sensitivity and Monte Carlo Analysis in R using package FME. In FME. Cran.Rproject.

Swanepoel, N., P. H. Robinson, and L. J. Erasmus. 2016. Rumen microbial protein flow and plasma amino acid concentrations in early lactation multiparity Holstein cows fed commercial rations, and some relationships with dietary nutrients. Livest. Sci. 190:58-69. https://doi.org/10.1016/j.livsci.2016.06.001.

Taylor, P. M. 2014. Role of amino acid transporters in amino acid sensing. Am. J. Clin. Nutr. 99:223S-230S. https://doi.org/10.3945/ ajcn.113.070086.
Tovar, A. R., E. Avila, S. DeSantiago, and N. Torres. 2000. Characterization of methylaminoisobutyric acid transport by system A in rat mammary gland. Metabolism 49:873-879. https://doi.org/10 .1053/meta.2000.6731.

Waterlow, J. C. 2006. Protein Turnover. CABI Publishing, Cambridge, MA.

Wu, G. 2013. Amino Acids. CRC Press, Boca Raton, FL.

Wu, Y. P., S. G. Liu, Z. H. Huang, and W. D. Yan. 2014. Parameter optimization, sensitivity, and uncertainty analysis of an ecosystem model at a forest flux tower site in the United States. J. Adv. Model. Earth Syst. 6:405-419. https://doi.org/10.1002/2013MS000298.

Yoder, P. S., T. Ruiz-Cortes, J. J. Castro, and M. D. Hanigan. 2019. Effects of varying extracellular amino acid profile on intracellular free amino acid concentrations and cell signaling in primary mammary epithelial cells. J. Dairy Sci. 102:8977-8985. https://doi.org/ $10.3168 /$ jds.2018-16122 